Portland State University

PDXScholar

\title{
Do Fungal Symbionts of Salt Marsh Plants Affect Interspecies Competition?
}

Vanessa Robertson-Rojas

Portland State University

Follow this and additional works at: https://pdxscholar.library.pdx.edu/open_access_etds

Part of the Plant Sciences Commons, and the Soil Science Commons Let us know how access to this document benefits you.

\section{Recommended Citation}

Robertson-Rojas, Vanessa, "Do Fungal Symbionts of Salt Marsh Plants Affect Interspecies Competition?" (2020). Dissertations and Theses. Paper 5579.

https://doi.org/10.15760/etd.7451

This Thesis is brought to you for free and open access. It has been accepted for inclusion in Dissertations and Theses by an authorized administrator of PDXScholar. Please contact us if we can make this document more accessible: pdxscholar@pdx.edu. 
Do Fungal Symbionts of Salt Marsh Plants Affect

Interspecies Competition?

by
Vanessa Robertson-Rojas

A thesis submitted in partial fulfillment of the requirements for the degree of

Master of Science

in

Environmental Science and Management

Thesis Committee:

Catherine de Rivera, Chair

Sarah M Eppley

Jennifer Morse

Portland State University

2020 


\section{Abstract}

The effects of arbuscular mycorrhizal fungi (AMF) as salt marsh plant symbionts may have significant effects on landscape scale distribution patterns and plant-related ecosystem functions that are important to estuarine habitats. This work investigates the effects AMF have on Phalaris arundinacea, Deschampsia cespitosa, and Juncus balticus when grown in a common garden experiment. Plants were grown with and without AMF inoculation in both polyculture and monoculture communities and examined for a variety of response variables that represent different competition strategies. Factorial ANOVA analysis revealed a significant three-way interaction among fungal treatment type, community type, and species for chlorophyll fluorescence, which measures plant stress. Plant stress was higher in J. balticus without inoculation than in inoculated conspecifics, especially when grown in the polyculture community. Conversely, plant stress was slightly lower in the invasive grass, $P$. arundinacea without inoculation when grown in a community compared to the other combinations. Posthoc tests did not detect any major differences between treatments in Deschampsia cespitosa or in monocultures. Graphs of the other measures of response, ones aimed at determining differences in competition, looked very similar across treatments within a species and between polyculture and monoculture, and did not warrant statistical analysis of the effect of inoculation with AMF. This experiment indicates that fungal inoculation may offer stress amelioration through photosynthetic pathway II to Juncus balticus and may have the opposite effect of non-native Phalaris arundinacea. Given that AMF may have species-specific effects, commercial inoculants, which often do not specify the origin of their soil fungi, could be 
advantageous to restoration plantings in salt marsh habitats when the native species gain more advantage than locally invasive ones. With increased value placed on salt marsh habitat restoration, these findings serve as an important first step towards determining which AMF-species combinations can benefit salt marsh restoration. 


\section{Dedication}

This text is dedicated to the female scientists that pioneered the access of professional work in this field for my generation. All of your sacrifices, hardships, and oppressions will not be wasted. Thank you for everything you have done. 


\section{Acknowledgements}

I would like to express my gratitude to Dr. Catherine de Rivera for her role as my advisor, committee chair, and as mentor beginning in 2012 during my undergraduate degree and continuously through my master's degree completion in 2020. You have provided both insight and pragmatism, but I value your dedicated approach to collaborative and thoughtful science most. Working alongside you has changed my life and understandings about learning, teaching, and the contemplation of the natural world. Thank you also to Dr. Sarah Eppley and Dr. Jennifer Morse, my committee members who have provided deeper insight into ecological systems through their respective areas of expertise. Each of you were exceptionally enjoyable to work with, and I thank you for your critique and support. Thank you to Dr. Daniel Ballhorn, Linda Taylor, the Rae Sellings Seedbank, the de Rivera Lab, Rayna Koberstein, Olamide Alo, Elissa ConnolyRandazzo, Sara Volk, Robyn Dove for all your thoughts and helping hands. Each person or group mentioned here has generously offered their time, thoughtful pragmatism, and expertise in their respective fields that allowed me to complete this work to a profoundly improved degree. I am also grateful for the support of my family and friends who have shown unconditional support in the kindest ways. Lastly, I am indebted to the salt marsh plants who have brought the deepest joys to this work, thank you for all that you are. 


\section{Table of Contents}

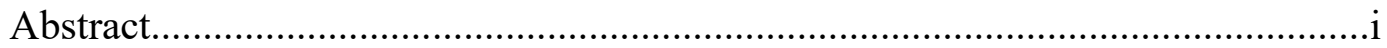

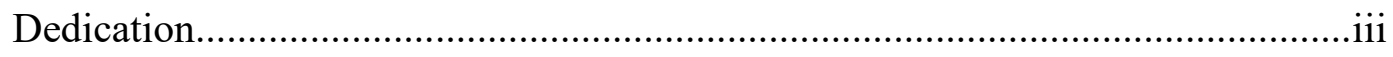

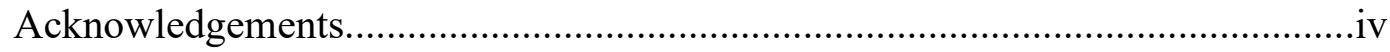

List of Tables ........................................................................................

List of Figures...........................................................................................

List of Abbriviations................................................................................ vii

Chapter 1 Study Introduction..................................................................

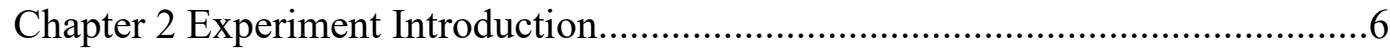

Chapter 2 Experiment Methods................................................................ 13

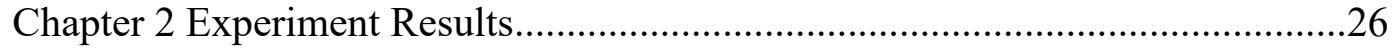

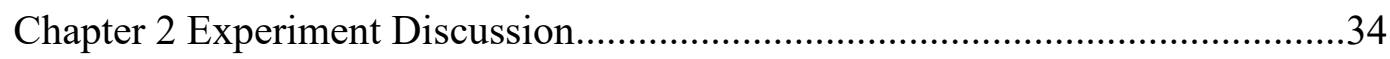

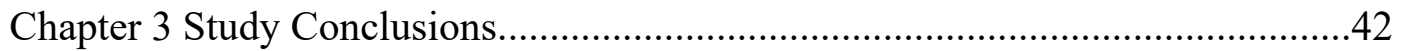

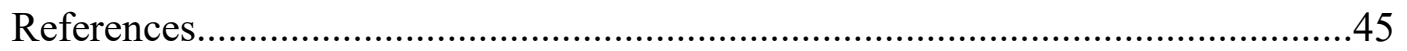

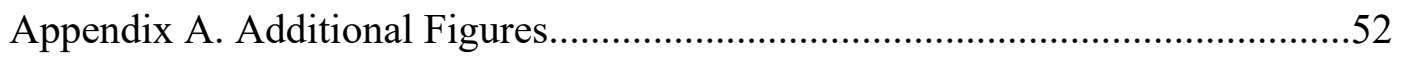




\section{List of Tables}

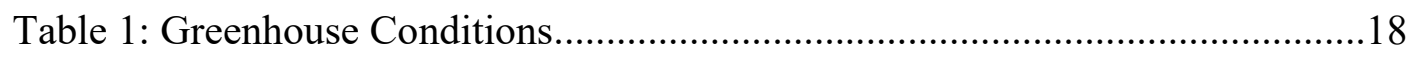

Table 2: Variables and Associated UAST Strategy.................................................18

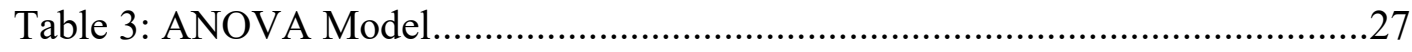

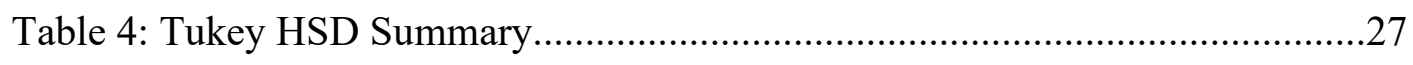

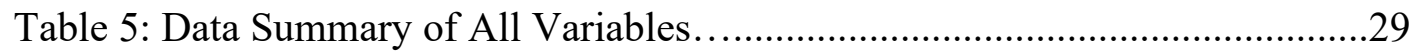

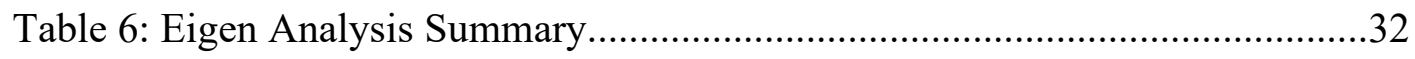

Table 7: Root Colonization by AMF Summary.....................................................33

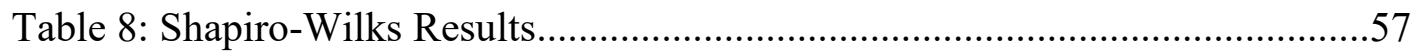




\section{List of Figures}

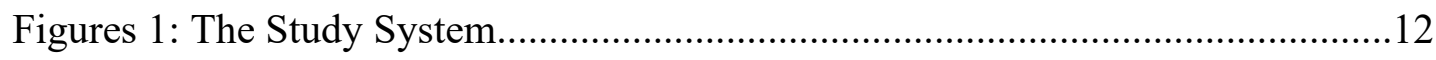

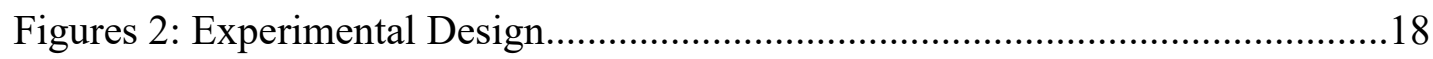

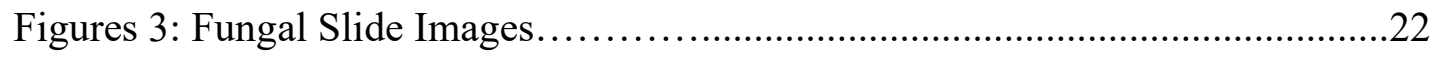

Figures 4: Histograms of All Chlorophyll Fluorescence Treatments........................24

Figures 5: Chlorophyll Fluorescence Across All Treatments.................................28

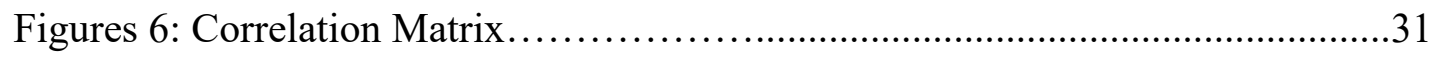

Figures 7: QQ Plots of All Measured Variables..................................................52

Figures 8: Histograms of All Measured Variables................................................55

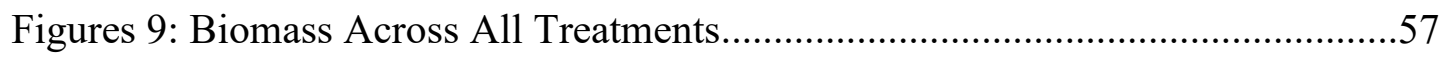

Figures 10: PCA Analysis of All Measured Variables..........................................58

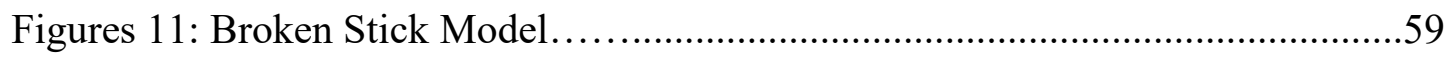




\section{List of Abbreviations}
$\mathrm{AMF}$
Arbuscular Mycorrhizal Fungi
$\mathrm{C}^{\mathbf{o}}$
Degrees Celsius
C3 In reference to plant fixation method, Carbon fixation pathway 3
(Fv/Fm) Maximal possible fluorescence value over the measured fluorescence value
h Hour(s)
IPCC International Panel for Climate Change
N Number of samples
PCA Principle Component Analysis
PSII Photosynthetic pathway two
PNW Pacific Northwest
RCI Relative Competition Index
SD Standard Deviation
UAST Universal Adaptive Strategy Theory 
Chapter 1: Study Introduction

The ecosystems services that salt marshes provide on the west coast in concurrence with their limited range compounds the need for understanding underlying function and habitat conservation. Salt marsh conservation should entail both the maintenance or restoration of physical area and the integrity of the complex systems seen in hydrological, vegetative, and pedological processes (Heider and Sinks 2018). Maintaining the integrity of these processes would ensure continued ecological services procured from these habitats. Within North America salt marsh habitat area is less expansive in the Pacific Northwest (PNW), but these rarer habitats remain functionally important in a variety of ways by providing rearing habitat, storm buffering, nutrient cycling, and carbon storage (Zedler and Kercher 2005). Salt marsh flora and fauna are uniquely productive in the PNW given their smaller spatial distribution (Brown and Ozretich 2009, Eliers 1987, Ewing 1986), which ultimately increases the value placed on the remaining areas of this habitat that occurs solely within estuaries.

The imminent rise of global sea levels, although variable across coastal topographies, will compound the need for thoughtful land management to secure the continued existence of salt marshes and their associated benefits. Rising ocean elevations will flood current marshes that occur directly above the intertidal area, and their persistence as coastal habitat will depend on whether or not salt marshes will accrete vertical elevation through particle settling and vegetative entrapment of seaborn soil particles and organic particles, or lateral migration to upland areas via seed transport or vegetative expansion (Borchert et al. 2018). Coastal areas surrounded by roads, levees, 
converted lands (such as agriculture or residential land use) or other anthropogenic structures will be constricted by lateral migration, and thus will only persist if vertical accretion matches sea level rise (Cosby et al. 2016, Raposa et al.2013). This limitation of upland migration trajectories within PNW coastal marshes will exacerbate the fragility of these habitats' ability to persist under climate change conditions, further landscape conversion and development, and natural evolution over time, all of which can alter the functionality and persistence of salt marshes.

Both scenarios that describe how salt marsh elevation could rise to keep pace with SLR depend on the performance of vegetative processes that have historically occurred (Raposa et al. 2013). These processes occur across a small range of elevation that typically span a relatively wide spatial area due to the flat topography that occurs over the majority of the marsh platform, with exceptions around small incised channel systems, sandy dropout locations around points of slowed water movement, and where debris is deposited within the marsh (Seliskar and Gallagher 1983). Despite occurring within a narrow elevational band, salt marshes contain several distinct bands of vegetative zones that form in response to the level of flooding that differs significantly within mere inches of elevational gain across the marsh platform. The marsh area that occurs the lowest in the elevational profile typically experiences the most tidal action, dropout and deposition of sand particles, the highest saline concentration of brackish water, and the most exchange of debris transport (Seliskar and Gallagher 1983). This area is submerged during diurnal flooding, contains un-oxygenated soils (anoxia), remains sparsely vegetated by algae/seaweeds and is commonly referred to as the mudflat. Above this area is the low 
marsh, which is also flooded daily but receives moderate tidal action that is often seasonally dependent. This marsh area also contains anoxic soils and is dominated by unique vascular plants that tolerate these conditions through a variety of stress tolerance adaptations. Species of Salicornia in both the PNW and throughout the world are common and characteristic of low marsh vegetation that dominate spatial area in 5-30 ppt salinity. These plants can actively prevent salt entrance into their roots, sequester intracellular salts, and/or secrete salts through glands (Katschnig et al. 2013). The high marsh persists along the uppermost boundary of tidal influence and receives the least amount of flooding, tidal action, and slight oxygenation of soils during the summer season (Bertness and Ellison1987). Due to the slight relief of flooding, salinity, and tidal action stress the high marsh plant community is more productive with vegetative material both above ground and below. It is important to note that throughout the marsh oxygenation can occur locally when burrows are created by soil infauna, crustaceans, or other animals. This occurrence creates a slightly ameliorated condition for both flora and faunal nearby and leads to increased metabolic production.

Within these zones plant diversity remains low because few plants are adapted to survive in stressful marsh conditions, but vegetative production can be prolific amongst plants that do survive in the marsh because they are released from intense competition pressure. Each zone may contain only a few dominant plant species that proliferate under this release from competition, and the remaining interactions amongst these plants are known to benefit from inter-taxa facilitation (Bertness 1994). Within a zone, plants often form bands of vegetative cover within their narrow elevational bands of dominance. It can 
be posited that stress adaptations and strategies for persisting in the salt marsh determine vegetative success, and therefor determine the zonation patterns of a given marsh (Bertness and Ellison 1987, Veldhuis et al. 2019).

Fungi that persist in the soil often form relationships with the flora and fauna of the salt marsh and can impact plant communities in a variety of ways (Peay et al. 2008). Their involvement with plant physiological processes can alter plant competition (Burke et al. 2002), facilitation, reproduction, and the community structure within the marsh. Arbuscular mycorrhizal fungi (AMF) alter the plant interactions and life processes by forming connections with plant roots below ground and altering nutrient uptake and stress mitigation centralized around these below ground interfaces (Hoeksema et al. 2010). The composition and abundance of AMF communities can vary across space and time within the salt marsh and are known to respond to inundation levels, salinity (Aggarwal et al. 2012), and nutrient availability or limitation within the soil profile (Carvalho and Caçador, 2001, Carvalho 2003). While it is known that even minimal presence of fungi can alter plant interactions in the marsh (Wang et al. 2016), specific competition or facilitation interactions contextual to the salt marsh habitat require further investigation.

In particular, the degree of effect that AMF can have on plant competition within PNW salt marshes that are nutrient limited, frequently inundated, and incur year-round salinity exposure remains unstudied. This work investigates three strategies plants may express in communities under these conditions as proposed by Grimes (1977). Grimes proposed the Universal Adaptive Strategy Theory (UAST) which describes how, in the presence of physiological stress and disturbance, three adaptive strategies emerge in 
plants. In low disturbance/low physiological stress situations, competition becomes imperative for persistence on the landscape. Plants that proliferate under low disturbance but high physiological stress employ stress tolerance to persist. Lastly, high disturbance and low stress results in the proliferation of ruderal or pioneer life strategies to persist on the landscape. High disturbance paired with high physiological stress prevents any plant recovery and is not considered in this framework. It is important to note that all three of these strategies are proposed as extremes, and most plants employ one to three of these strategies in variable proportions, and that their allocation balance may differ by plant life stage and habitat seral stage (Grimes 1977). Lastly, it is important to note that this framework differs from the examination of how plants interact more broadly, such as when considering competition, facilitation, and mutualism more broadly in that it specifically explores the type of competition taking place between individual plants and/or broader plant groupings. This work poses that where interspecies competition occurs in the salt marsh, AMF may have different impacts on plant competition as measured by competition, stress tolerance, and ruderal strategies as described by the UAST framework. 
Chapter 2: Experiment Introduction

Both plants and soil microbes are crucial components of salt marsh habitats that respectively perform primary production and decomposition in marshes and connect the biotic and abiotic parts of the marsh system (Odum 1988). Primary production and decomposition processes support a wide variety of uniquely valuable habitat functions in estuarine habitats but can vary across elevation gradients (Seliskar and Gallagher 1983, Ewing 1986, Bernard et al. 1988). These functions include juvenile rearing habitat for fish (Gray et al. 2002) and birds (Weller 1994), while sequestering carbon, buffering storms, mitigating floods, and nutrient retention (Costanza et al. 1997, Nelson and Zavaleta 2012). They persist sparsely across the landscape in the PNW due to a narrow coastal shelf (Torio et al. 2013) and decades of draining and diking salt marsh habitats. The International Panel for Climate Change (IPCC) highlights the relative importance of these heterogeneous ecosystems, and how they are disproportionately impactful despite their small spatial areas (Weis et al. 2016), which engenders great interest in conservation and restoration of marsh habitat. A small variety of stress tolerant plants, sometimes with the help of mycorrhizal fungi, compete as they serve as the foundation of this stressful yet productive and important ecosystem.

Salt marshes present a uniquely stressful environment for plants to persist due to exposure to estuarine water and soil, water-logged, anoxic soils, nutrient limitation, and daily changes in water levels within an estuary, all of which contribute to plant stress (Bertness and Hacker 1994). Specialized physiological adaptations allow a limited assemblage of plants to persist in these areas (Bertness and Hacker 1987, Canepuccia et al. 
2013). Some salt marsh plants have mycorrhizal associations with soil fungi that result in mutualism and/or parasitism (McHugh et al. 2004, Zhang et al. 2014). Zhang et al. found that these relationships have been shown to impact plant competition differently in a removal experiment including 5 marshland species, and that results were species specific and based on dominance/sub-dominance relationships between the study species. Mycorrhizal fungi benefit their host plants with nutrient acquisition in exchange for carbon while a nearby non-symbiotic plant may struggle to acquire nutrients (Lin et al. 2015). In addition, AMF can benefit a subdominant host in a dominant/subdominant plant relationship where the fungal symbiont parasitizes a dominant plant by acquiring carbon from it and supplying those metabolic units to a neighboring subdominant plant (Lin et al. 2015). AMF effects on plant growth can vary in response to environmental factors such as salinity or anoxic soils (Fraser et al. 2005, Heeksema et al. 2010).

Mycorrhizal effects on plant nutrient acquisition and allocation is an emerging field of ecophysiology that has explored pathways from soil to internal cellular structures, macronutrient ratios and volumes, allocation of nutrients to various plant structures, and nutrient effects on reproductive success. Cumulatively, these various fungal symbiont effects on plants may alter competition strategy and success in a myriad of ways. Grimes' Universal Adaptive Strategy Theory (UAST) emphasizes the use of specific adaptive strategies by plants to persist on the landscape (Grime 1979). These strategies include ruderal, stress tolerance, and competition and are used here as a framework for examining competition in the high salt marsh. Ruderal plants are particularly resilient to disturbance such as browsing, burning, or other events that damage the plant, while stress tolerant 
plants are able to persist in the presence of photosynthetically restrictive phenomena such as drought, shade, or high salt concentrations. Lastly, the UAST competitor strategy (not to be used interchangeably with more general primary competition strategies) occurs in plants that most effectively exploit available resources. This last UAST strategy can occur under stressful conditions or in the presence of disturbance and is specifically observed when plants exploit resources exceptionally well under any conditions (Grime 1979, Grime 1987.

Banded distributions of plant species in marshes occur when plant functional types respond to environmental conditions (Lin 2015) that are present at different elevational zones (Bertness and Sally 1994). These bands often differentiate between the low and high marsh, where conditions can differ due to elevational differences. For example, the high marsh during spring freshet in the PNW presents lower stress pressure than the low salt marsh due to rainfall and subsequent reduction is the salinity of surface water and soil pore water. Thus, the high marsh becomes a more hospitable place for plants to establish, and many plants have specially adapted to compete well for resources and dominate this elevational band (Bertness \& Hacker 1987). These more benign circumstances increase the instances of interspecies competition (Grimes 1979), of which the most dominant plants are of interest due to their increased biological presence and impacts. The outcomes of interspecies competition in the high marshes, and therefore high marsh diversity and function, can be altered by plant interactions with fungal symbionts (Burke et al. 2002, Fraser and Feinstein 2005, Hoeksema et al. 2010). We do not know of any research currently that has observed the effect of mycorrhizal fungi on high marsh plant species 
and their competition interactions in the current study region, despite the known value of salt marsh habitat functions in the PNW. Current practices in plant nurseries that use commercial inoculants to improve belowground plant health may be introducing locally non-native fungal communities to highly managed landscapes and habitat restoration sites alike. Halophytic and hydrophytic graminoids (grasses, sedges, and rushes) occupy much of the herbaceous layer in the high marsh, and thus are of great concern when planning for aerial cover of native plant species (Keammerer et al 2001, Lavergne et al. 2004).

Add paragraph about species within the marsh, review some salmon river lit, inroduce plant community, breifly decsribe three gramminoids examined here Research Questions and Hypotheses:

We conducted an experiment examining the effect of AMF on the adaptive strategies of salt marsh plants, especially its role on competition, using three common salt marsh species, Phalaris arundinacea, Deschampsia cespitosa and Juncus balticus. The three species included in this experiment dominate patches they occur in within the marsh, as documented by several monitoring studies at different timelines in additional to preproject data collected for this work (Frenkel et al. 1993, Gray et al. 2002). The overall plant community's diversity is somewhat limited by the environmental stressors described previously, but this work may offer insight to the boundaries where patches and bands of a singular species may meet another. A competition study would specifically investigate the way these three species may interact at the patch or boundary in the presence of AMF, which ultimately may impact the distribution of each species within the marsh. Thus, it is 
important to consider more than two plants in order to investigate a community, with or without fungi present, when grown with the same species or in a mixed community. We predict that AMF will impact these plants differently, due to their varying life histories and competition strategies, and will allow each plant to express one or multiple strategies differently when grown in the presence or absence of AMF.

We hypothesized that each species would respond differently to AMF inoculation when grown in a community of three plants as compared to being grown in a monoculture of three individuals of the same species. It is predicted that Phalaris arundinacea will have a significant response to inoculation. Up to $90 \%$ of roots were inoculated by AMF in freshwater wetland habitats in a study by Fraser and Feinstein (2005) that summarized the inoculation range in freshwater wetlands (such documentation in saline systems is currently unavailable). High levels of inoculation suggest that this invasive plant benefits from efficient nutrient acquisition across many different habitat ranges, including in the PNW (Annen et al. 2008, Barnes 1999). We also predicted that Deschampsia cespitosa, a dominant native to the PNW that is known to associate with AMF (Ingham and Wilson 1999, Olsson et al. 2008, Seliskar 2019) would also benefit from a fungal symbiont. Juncus balticus, another native plant that occurs commonly in freshwater systems, has received minimal study with regards to association with AMF; however, showed comparatively low fungal association of $15-18 \%$, but received substantial growth benefits from this relationship (Tadych and Blaszkowski 2014). Thus, it was predicted J. balticus would be positively affected by AMF inoculation if colonized. This slower growing plant does not compete well for space in short periods of time and given the shorter duration of 
this study compared to its longer lifespan, J. balticus was predicted to have low colonization but marginal benefits from AMF. Cumulatively, we predict that these differing effects of fungi on unique plant species will all be more demonstrable in polyculture treatments where interspecies competition for space and resources will occur more intensely. Additionally, we predicted that each of the three species examined will demonstrate different levels of AMF inoculation/colonization in their roots after inoculation treatments in the greenhouse, based on documented cases of AMF colonization seen in multiple studies (Ingham and Wilson 1999, Olsson et al. 2008, Seliskar 2019, Fraser and Feinstein 2005). Each plant also demonstrates different competition strategies when documented in freshwater systems which will be subsequently described (Grimes, 1979).

To investigate the listed research questions a common garden experiment was conducted in a research greenhouse. Three plants found commonly in an Oregon salt marsh were grown in polycultures and in conditions replicating PNW coastal marsh conditions with and without fungal symbionts. Each of the three species was grown in a corresponding monoculture which functioned as a control for comparison to the polyculture plant responses. Each plant in each treatment was measured for various responses to the fungal treatment to detect differences in plant competition in the presence of AMF. 
Figure 1. The Study System. A conceptual model of the estuarine system components as relevant to the study design. Plants can be seen growing across a shallow elevational gradient and forming patches and zones of monoculture stands. Below ground plant roots can be seen to grow among a thick organic layer (seen in dark black) that contain higher salt concentrations, anoxic soil, and fungal symbionts around the plant root. Each plant has different adaptive traits and strategies seen in intra and inter-species competition, as well as different relationships with fungal symbionts found in the marsh soil. 
Chapter 2: Experiment Methods

Field Site

The marsh in the Salmon River Estuary located in Otis, Oregon (N 45.034157, E 123.982552) was used to inform the greenhouse conditions. Environmental conditions including $\mathrm{pH}$, temperature, and salinity were documented in February of 2019, and are summarized in Table 1. Thirty 1x1 m plots with 100 percent cover of each species were located within the high marsh. A soil core was taken from each plot at the base of 5 different plants within each plot to obtain the roots of each plant. A slurry was created from soil from each core mixed with deionized water, using $50 \mathrm{~g}$ of soil from each core (Sparks 2009, p.417-422) and a separate $30 \mathrm{~g}$ of soil to measure in site in situ $\mathrm{pH}$ (Sparks 2009, p.485-489).

Study Species

The study species examined here include Turtle hair grass (Deschampsia cespitosa (L.) Beauv), Baltic rush (Juncus balticus), and Reed canary grass (Phalaris arundinacea). All three species considered occur in the Salmon River salt marshes, utilize C3 carbon assimilation pathways, are perennial, and dominate patches of open area at various elevations above mean high water. $P$. arundinacea is found in the uppermost regions of the marsh, atop a vegetative mat that does not experience frequent inundation from brackish water, while $D$. cespitosa is commonly found along marsh drainage channels that drain upland area, and thus contain slightly less saline water (1-2.5 ppt, unpublished field 
data). Juncus balticus occurs in patches throughout the low and high marsh that are occasionally mixed with smaller patches of gramminoids and forbs.

Deschampsia cespitosa is globally distributed bunchgrass that is found in freshwater wetlands as well as salt marshes along the west coast, across North America, and on other continents containing temperate climates and wetland habitats (Keammerer 2011, Grimes 2007 p.220). Most study on this species has occurred in freshwater systems and indicates that $D$. cespitosa uses all three competition strategies, but most often employs stress tolerance strategies to persist and even dominate in landscapes. Stress tolerance may be a particularly successful strategy to this plant that can be particularly long lived, with an individual bunch aging $>30$ years (Grimes 2007 p.220). In freshwater wetlands, root inoculation by AMF can range widely (7-54\%), which is likely related to the expansive habitat range of the grass (Ingham and Wilson 1999, Olsson et al. 2008, Seliskar 2019). AMF colonization of D. cespitosa and impacts on competition success have not yet been studied.

Juncus balticus is a globally persistent bunch forming rush seen across variable habitats that include saline influenced and freshwater wetland habitats (Hurd et al. 1992) and is native to the PNW. In a study replicating coastal dune habitats, AMF association with Juncus spp. was documented, and suggested that increased root colonization occurs as soil flooding is reduced (Tadych and Blaszkowski 2014). A field study conducted across broad genera of coastal plants demonstrated that of Juncus spp. had a low relative competition index (RCI) when compared to 40 other species, including $P$. arundinacea in Nova Scotia, Quebec, and Ontario, Canada (Gaudet and Keddy 1995). While this species 
of Juncus's competition strategy has not yet been documented, a field study focusing on nitrogen uptake between Typha spp. and hybrids and J. balticus showed a low $\mathrm{N}$ uptake by J. balticus, indicating that it may employ ruderal or stress tolerance strategies instead of competition to establish and persist on the landscape (Larkin et al. 2012). There are no additional works specifically focusing on J. balticus ecology in salt marshes, or in relation to AMF's ecological impacts.

Phalaris arundinacea, a non-native mat forming grass, has become dominant in many freshwater wetlands worldwide due to its competition success (Grimes 2007 p.430). Recent literature has documented this species expansion into estuarine habitats along upper marsh fringes (Annen et al. 2008, Barnes 1999). Phalaris arundinacea is known to associate with AMF in variable freshwater habitat types and have shown 3-90\% root colonization, 50\% on average, across different habitat types (Fraser and Feinstein 2005, Bauer et al. 2003). In the native European range of $P$. arundinacea, this plant is known to use the competition strategy through its strong rhizomatic reproduction that creates large clonal patches to persist in wetland and wetland transitional habitats, which is likely its competition strategy in invaded ranges (Martina and von Ende 2013, Grimes 2007 p.430). There is currently no work pertaining to $P$. arundinacea competition specifically in the presence of AMF in salt marshes.

Greenhouse Experiment

A greenhouse experiment was conducted to examine the effect of AMF inoculation on three high marsh species, grown both individually and together in a community. 
Monocultures of D. cespitosa, J. balticus, and P. arundinacea and corresponding polycultures of all three species each had an inoculated and a sterile treatment (Figure 2). Each of the resulting eight treatment groups initially had 30 replicate pots $(\mathrm{N}=240$ pots) and were used in a 3-factor fully crossed design (species, culture, fungal inoculant factors). The 240 pots were spread out evenly across four $1.2 \times 20 \mathrm{~m}$ benches in a random block design. Environmental conditions in the greenhouse included controlled temperature at a range of $18-30^{\circ} \mathrm{C}$, humidity at $>80 \%$, with natural light subsidized by artificial light when needed for $16 \mathrm{~h}$ daily throughout the entire greenhouse room.

Plants were grown for a 70-day period with most conditions replicating reference marsh conditions (Table 1). Plants were germinated under spring/early summer lighting conditions (18 h lights on, $6 \mathrm{~h}$ lights off), and between 24 and $29^{\circ} \mathrm{C}$ ), weighed, and seedlings of the same weight (within $0.01 \mathrm{~g}$ ) were transplanted into each pot. Plants were placed equidistant from each other in a triangle shape, $3 \mathrm{~cm}$ apart. An 80:20 ratio of sterile sand to vermiculite was used as a growth medium. All sand was washed with a 10:1 water to bleach ratio, rinsed with a $10 \%$ Benomyl fungicide solution and allowed to rest for 36 hours before transplanting. Each pot was filled with the growth medium to within 2.5-3.5 $\mathrm{cm}$ of the top of the pot then placed in a 9.46L reservoir. The water in the reservoir was filled as needed to maintain a water level within $7 \mathrm{~cm}$ of the top of the substrate profile. A layer of landscape fabric was placed at the bottom of each pot to prevent sand from draining out of each pot, while maintaining connection with the water reservoir around the pot after Burke et al. (2002). With the goal of replicating reference conditions of limited nutrients, plants were not fertilized. Any nutrients present came from the initial 
sand/vermiculite mix or the inoculation treatments that occurred every two weeks (see below). Salinity, $\mathrm{pH}$, and nutrient levels were monitored throughout to maintain similar conditions to the reference marsh.

Soil was collected from the reference marsh and applied to all treatments (sterilized or left inoculated) on order to introduce AMF from the restored marsh to the appropriate treatments. Seventy grams of soil from the reference marsh was collected 48 hours prior to soil inoculation treatments via collection of soil cores within monocultures of plant species. This soil was collected by coring at the base (within $5 \mathrm{~cm}$ of each plant base) of all three species in the marsh, each with 30 replicates that were combined, homogenized, and mixed with a 1:3 soil: water ratio to create a slurry. Cores were collected within the top $10 \mathrm{~cm}$ of the marsh soil profile to capture the most active area in the soil profile for AMF. The total volume of soil was homogenized, then divided in half. One half was sterilized with 10\% Benomyl fungicide solution to reduce unintentional AMF colonization, and then applied to non-fungal treatment pots, $70 \mathrm{~mL}$ of slurry was applied to each pot. The second half of the soil slurry was applied directly to the fungal treatment plots as in-tact, unsterilized soil to provide inoculation exposure to the fungal treatment pots which also received $70 \mathrm{~mL}$ of slurry in each pot. The application of $70 \mathrm{~mL}$ of an inoculant or a sterilized soil slurry was replicated every 14 days after initial transplanting. 


\begin{tabular}{|ccc|}
\hline $\begin{array}{c}\text { Polyculture } \\
\text { (all species) }\end{array}$ & $\begin{array}{c}\text { Monoculture } \\
\text { (Deschampsia }\end{array}$ & $\begin{array}{c}\text { Monoculture } \\
\text { (Juncus balticus) }\end{array}$ \\
& & \\
& & \\
\end{tabular}

Figure 2. Experimental Design. Shows all potted treatments including culture (Poly culture or Monoculture), individual species included in each monoculture (Deschampsia cespitosa, Phalaris arundinacea, and Juncus balticus), and fungal treatments noted as +AMF for treatments receiving inoculation, and -AMF for treatments receiving fungal sterilizing treatments. All 8 treatments were replicated 30 times, which resulted in 240 pots containing 3 plants, and thus 720 plants were included altogether in this experiment.

Table 1. Greenhouse Conditions. Environmental conditions of the reference site were approximated in the greenhouse. Five of these conditions were closely matched and represent the conditions most likely to occur for plants in a similar early life stage during the spring freshet season, exceptions are italicized.

\begin{tabular}{|l|l|l|}
\hline Condition & Reference Marsh & Greenhouse \\
\hline Light & Early spring conditions & Early spring conditions (shade cloth) \\
\hline Temperature & Below $30^{\circ} \mathrm{C}$ & Below $30^{\circ} \mathrm{C}$ (temperature control) \\
\hline $\mathrm{pH}$ & $6-6.5(0.22)$ & $\begin{array}{l}6.6 \text { (naturally occurred in pots) }(0.27 \\
\text { STDV) }\end{array}$ \\
\hline Salinity & $2.9 \mathrm{ppt}(0.28 \mathrm{STDV})$ & $2.6 \mathrm{ppt}$ on average $(0.19 \mathrm{STDV})$ \\
\hline Nutrients & Limited (literature-based observation) & Limited (sand substrate, no fertilizer) \\
\hline Soil Texture & Clay, humus dominant & Sand/Vermiculite mixture \\
\hline Diurnal Flooding & Natural flooding regime & Consistent water levels \\
\hline
\end{tabular}


Table 2. Variables and Associated UAST Strategy. The table below lists all plant variables measured and their associated adaptive strategy as theorized by Grimes (1979).

\begin{tabular}{|l|l|}
\hline Variable & Associated UAST Strategy \\
\hline Canopy Cover & Competition (horizontal space) \\
\hline Plant Height & Competition (vertical space) \\
\hline Number of Leaves & Competition (vertical and horizontal space) \\
\hline Number of Dead Leaves & Ruderal (ground mat material) \\
\hline Chlorophyll Fluorescence & Stress (photosynthetic production) \\
\hline Relative Competition Intensity & All (biomass between communities) \\
\hline Root Weight & All (biomass allocation to roots) \\
\hline Shoot weight & All (biomass allocation to shoots) \\
\hline Total Biomass & All (biomass allocation of each plant) \\
\hline Root: Shoot Ratio & All (biomass allocation between above and below ground material) \\
\hline
\end{tabular}

Plant height, canopy cover, and number of leaves were measured every 17 days during the experiment. A photograph of each pot was taken during each sampling period. Environmental conditions were monitored continuously, and plants were watered as needed to maintain pot reservoir fullness throughout the experiment. The experiment ended at the pre-determined cut-off, when the average canopy cover exceeded $75 \%$ and roots began to grow out of the bottom of pots, which occurred at 70 days.

Additional variables such as number of dead leaves, chlorophyll fluorescence (Equation 1), biomass, root weight, shoot weight, root/shoot ratios, and an RCI Index (relative competition intensity) were measured or calculated at the completion of the study due to the destructive or impractical nature of their respective sampling techniques during the experiment. 


\section{Equation 1: Chlorophyll Fluorescence $=F v / F m$}

Where $F v=$ variable fluorescence measured, and Fm= maximum fluorescence yield. This ration results in a unitless ratio that is always lower than 1.00, with healthy plants averaging 0.83 (Cendrero-Mateo et al. 2015)

Each pot's plants then were washed free of growth medium, and each plant's root mass was separated. The fresh weight of roots and shoots of each plant were then weighed separately. A root to shoot ratio was calculated (root: shoot). The relative competition intensity $(\mathrm{RCI})$ was calculated to create a relative competition index comparing biomass between communities.

(Equation 2, after Weigelt and Jolliffe 2003) seen below.

Equation 2: $R C I=\left[\left(P_{\text {mono }}-P_{\text {poly }}\right) / P_{\text {mono }}\right] * 100$

Where $P=$ Population metric (here seen as Final Biomass Weight (g)),

$$
\begin{aligned}
& \text { mono }=\text { Monoculture populations, and } \\
& \text { poly }=\text { Polyculture populations. }
\end{aligned}
$$

A subset of pot soils was sampled for salinity and $\mathrm{pH}$. After washing and weighing each plant, five pots were selected from each treatment using a random number generator for root colonization by AMF analysis. Final measurements of plant height, canopy cover, number of live, number of dead leaves, final weight, and plant stress as seen by 
chlorophyll fluorescence (Fv/Fm) were recorded. See Table 2 for UAST association of all measured variables.

Determination of Percent Root Colonization by AMF

To confirm the inoculation of targeted +AMF treatments, a subset of plant roots from all treatments were assessed for percent colonization by AMF after McGonigle (1989). Plant roots from treatments given 10\% Benomyl fungicide were also assessed in this way to observe any colonization of AMF structures. Root samples were separated from their respective aboveground biomass and washed clean of the growth substrate. The upper $20 \mathrm{~cm}$ of the root system (after Carvalho and Caçador 2001), was separated from the root mass and placed in a labelled histology cassette. Roots were cleared in a $10 \% \mathrm{KOH}$ solution for 15-20 minutes using a hotplate. Samples were washed free of KOH using Deionized (DI) water three times, soaked in a Trypan Blue Lacto-Glycerin Solution for 60 minutes, and then soaked in a $2 \%$ HCI solution for 30 minutes. The resulting stained root samples were then washed and stored by refrigeration at $0-1.6^{\circ} \mathrm{C}$ in Lactoglycerol until used for slide creation. The stained roots were cut into $5 \mathrm{~cm}$ lengths and were laid on a glass slide (each slide contained 5 rows of $5 \mathrm{~cm}$ lengths). Slides were viewed at 200x magnification over an 89-cell grid. All 89-cells in each slide grid was observed for presence of the fungal structures shown below. Arbuscules, vesicles, and/or hyphae, examples of which can be seen below in Figure 3, were counted individually per grid cell to determine the proportion of each root in each cell colonized by different AMF structures (McGonigle 1989). 


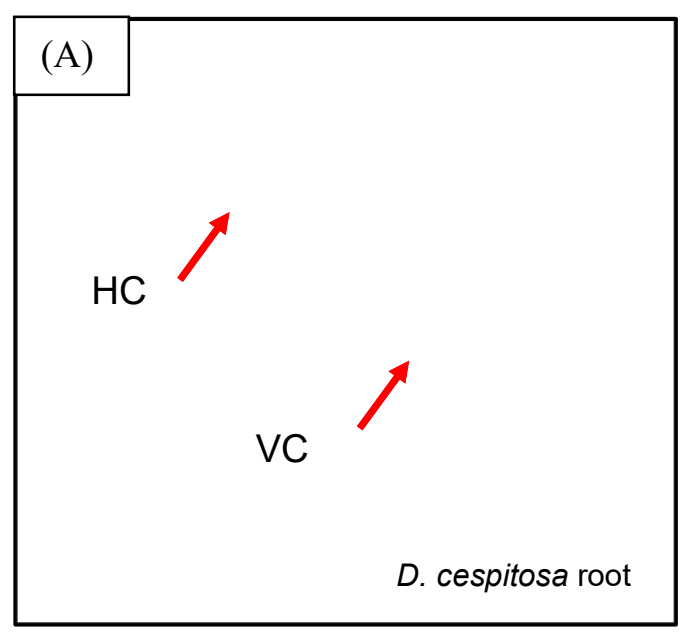

\section{(B)}
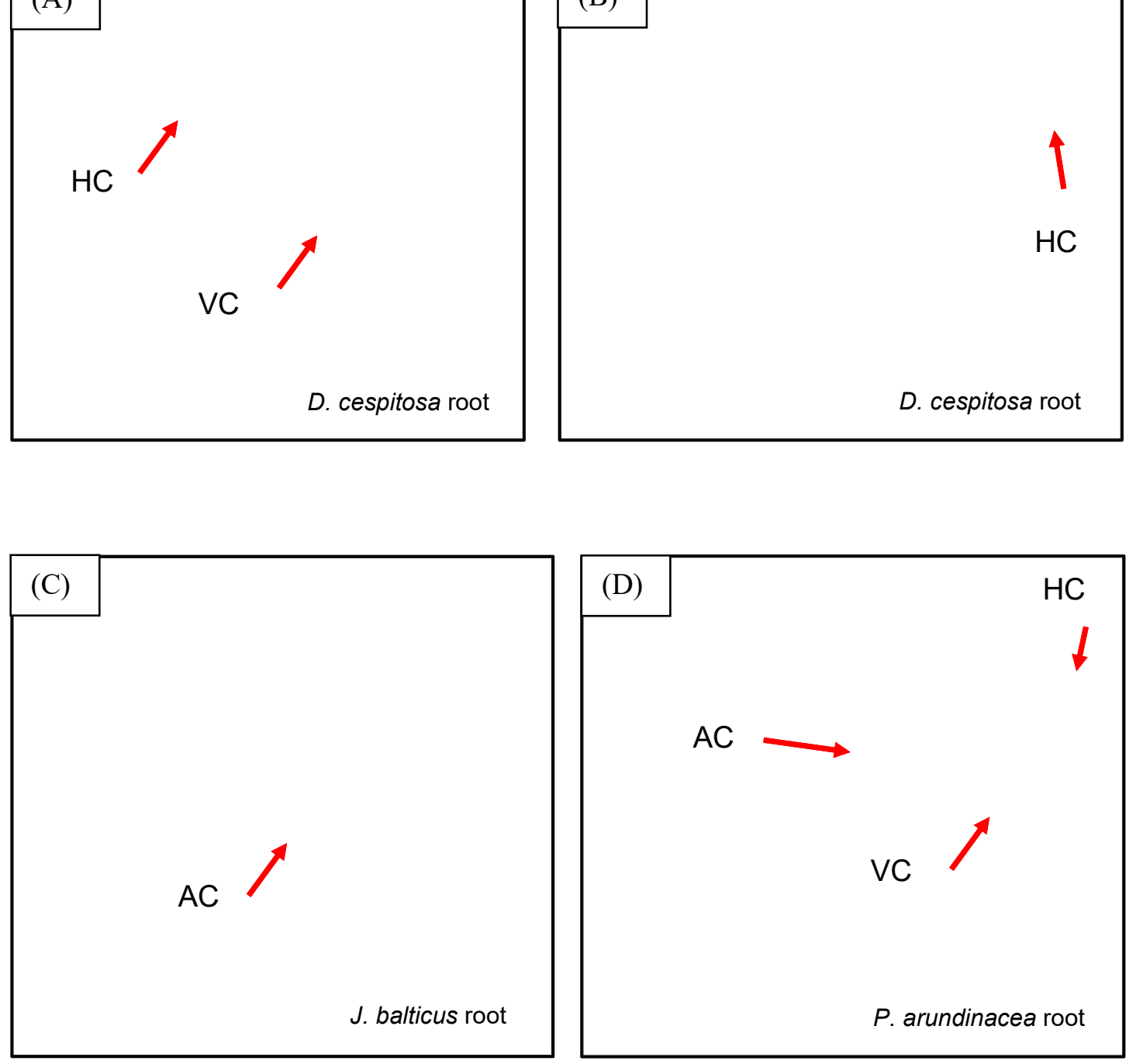

Figure 3. Fungal Slides. Different roots with AMF structures are shown in digital imagery taken through a dissecting microscope at $40 \mathrm{X}$ magnification. $\mathrm{AC}=$ Arbuscular Colonization, $\mathrm{VC}$ $=$ Vesicular Colonization, and $\mathrm{HC}=$ Hyphal Colonization. (A) Deschampsia cespitosa root with HC and VC, (B) Deschampsia cespitosa root with $\mathrm{HC}$ and unknown structure, (C) Phalaris arundinacea root with $\mathrm{AC}, \mathrm{HC}$, and $\mathrm{VC}$, and (D) Juncus balticus with $\mathrm{AC}$ in the bottom left.

Data Analysis

Data were analyzed in R Studio Version 1.2.1335. Records with missing values (NAs) were removed. Pots with plant mortality were removed from the study, which 
reduced replication from 30 to 25 . Variables that required post-experiment calculation included root: shoot ratio, RCI, and total biomass. The values for plants grown in monoculture were averaged per pot, creating a 1:1 comparison between each species in monoculture and polyculture. The data distribution of quartiles was summarized with QQ Plots, distributions were visualized with histograms, and a correlation matrix was created to examine the nature of collinearity between all variables (Figure 4). Shapiro-Wilks and Bartlett tests for normal distribution of data and equal variance (respectively) were performed on all variables to meet ANOVA test assumptions, using alpha $=0.05$ for all tests. 

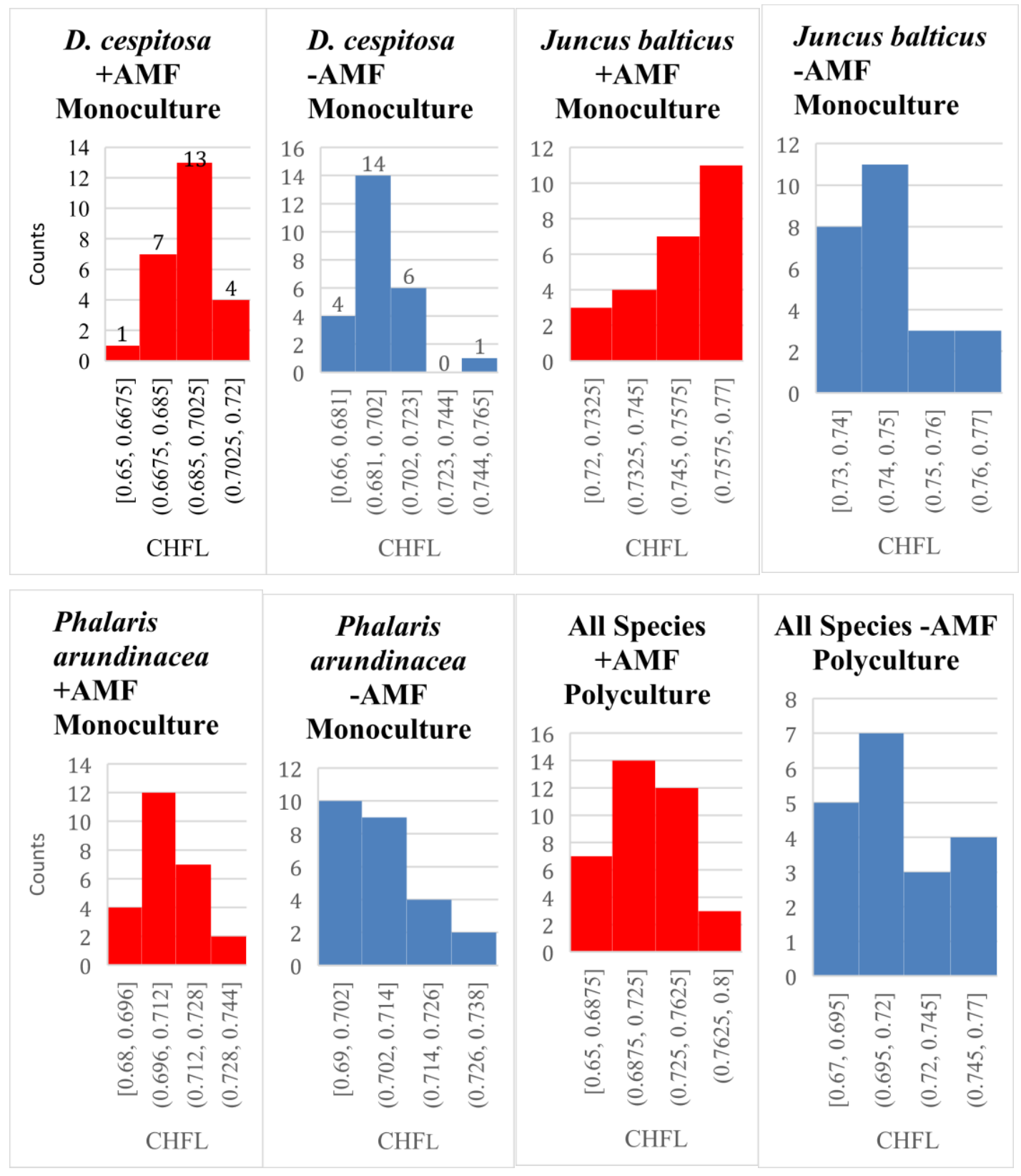

Figure 4. Histograms of All Treatments. Histograms of each treatment as seen by chlorophyll fluorescence (CHFL), which shows somewhat of a normal data distribution with exceptions in the $P$. arundinacea AMF Monoculture, J. balticus +AMF Monoculture, and J. balticus -AMF Monoculture treatments, which show a right skew distribution. Log, square root, and arcsine transformations were attempted to correct this skewness but did not yield results that pass test for normality. The last plot, QQ plots of chlorophyll fluorescence, shows that the data matches the theorical model to a reasonable extent. 
A principal component analysis (PCA) that uses orthogonal transformations was performed to identify potentially correlated variables to reduce data dimensionality, and to develop models that best explain the variance in the dataset. A PCA was performed (Appendix 1) and included a broken stick analysis to determine which principal components (PC's), and the variables they contained, to consider for statistical testing. The broken stick model showed that only PC1 and PC2 should be considered. An eigen analysis was conducted to observe which variables accounted for the most variance within PC's, which would suggest use of specific, singular variables for ANOVA analysis instead of analyzing all variables together in a MANOVA analysis. Additionally, histograms and boxplot representations of these variables were considered, from which only chlorophyll fluorescence, root weight, and canopy cover were considered for ANOVA analysis. Variables that were not weighted heavily (Table 6) in PC1 or PC2 were not included in ANOVA analysis. Chlorophyll fluorescence contained the most variance within PC1, while root weight and canopy both showed negative relationships.

PCA showed that chlorophyll fluorescence explained a larger amount of variance across all response variables, and thus a 3-way ANOVA test was conducted on this singular variable. A full ANOVA model was created that included community type, species identity, and $+\mathrm{AMF}$ or -AMF treatment type and all the interactions. A post-hoc Tukey HSD test was conducted to examine pairwise comparisons between all grouping variables created in this experiment. Bar charts, which demonstrate highly similar means among the treatments for the remaining variables, were made and can be seen in Appendix A. 
Chapter 2: Experiment Results

Chlorophyll fluorescence was significantly affected by AMF treatment (with or without mycorrhizal fungi), plant species (D. cespitosa, J. balticus, or P. arundinacea), and community (monoculture or polyculture), suggesting AMF has species-specific effects on chlorophyll fluorescence, or plant stress, across culture settings (Table 3, pvalue of 3-way interaction: 0.03). Chlorophyll fluorescence was shown to have differences between inoculation treatments in J. balticus in the polyculture communities (Table 4 and Figure 4). Indeed, Figure 4 shows that in polyculture communities J. balticus had a higher chlorophyll fluorescence reading (meaning lower plant stress) with AMF than without, and $P$. arundinacea exhibited the inverse, and both species exhibited a greater difference between the AMF treatments in polyculture than in monoculture. These interactions suggest that $J$. balticus experienced the most stress without AMF compared to with AMF when growing among other plant species; in contrast, $P$. arundinacea may have experienced the most stress in polyculture with AMF. The effect of AMF differed among species so these results were only apparent when examining the interactions among the three factors and the AMF treatment by species interactions (Table 3, $p=0.018$ for species * AMF treatment). 
Table 3. ANOVA Model. Three-way ANOVA full model for chlorophyll fluorescence where $\mathrm{p} \leq$ $0.05=*, \mathrm{p} \leq 0.01=* *, \mathrm{p} \leq 0.001=* * *$, and $\mathrm{p} \leq 0.0001=* * * *$. The test included all three grouping variables and shows significant three-way interactions where $\mathrm{p}=0.03 *$.

\begin{tabular}{l|l|l|l|l|l|}
\hline \multicolumn{1}{l}{ ANOVA Model } & Sum Sq & Mean Sq & F-value & Pr $(>\boldsymbol{F})$ \\
\hline AMF Treatment & 1 & 0.00001 & 0.000011 & 0.063 & 0.80 \\
\hline Species & 2 & 0.02716 & 0.013580 & 78.924 & $<2 \mathrm{e}-16^{* * *}$ \\
\hline Community & 1 & 0.00001 & 0.000010 & 0.057 & 0.81 \\
\hline $\begin{array}{l}\text { Treatment x Species } \\
\text { Treatment x Community }\end{array}$ & 1 & 0.00004 & 0.000040 & 0.235 & 0.63 \\
\hline $\begin{array}{l}\text { Species x Community } \\
\text { Treatment x Species x } \\
\text { Community }\end{array}$ & 2 & 0.00318 & 0.001590 & 9.243 & $0.0001 * * *$ \\
\hline
\end{tabular}

Table 4. Tukey HSD Summary. Pairwise comparisons between alike species in the same community, each with different inoculation treatments (+AMF or -AMF). (Species codes used for test summary $\mathrm{DECE}=$ D. cespitosa, $\mathrm{JUBA}=J$. Balticus, $\mathrm{PHAR}=P$. Arundinacea $)$. The comparison in bold draws attention to near differences of $J$. balticus between fungal treatments (-AMF or +AMF), while $P$. arundinacea differences between fungal treatments (-AMF or +AMF) are not significant but remain of interest.

\begin{tabular}{ll}
\hline Tukey HSD Summary & $\boldsymbol{P r}(>\boldsymbol{F})$ \\
\hline -AMF:DECE:MONO *+AMF:DECE:MONO & 1.00 \\
-AMF:JUBA:MONO *+AMF:JUBA:MONO & 0.99 \\
-AMF:PHAR:MONO *+AMF:PHAR:MONO & 1.00 \\
-AMF:DECE:POLY *+AMF:DECE:POLY & 1.00 \\
-AMF:JUBA:POLY *+AMF:JUBA:POLY & $\mathbf{0 . 1 2}$ \\
-AMF:PHAR:POLY *+AMF:PHAR:POLY & 0.35
\end{tabular}




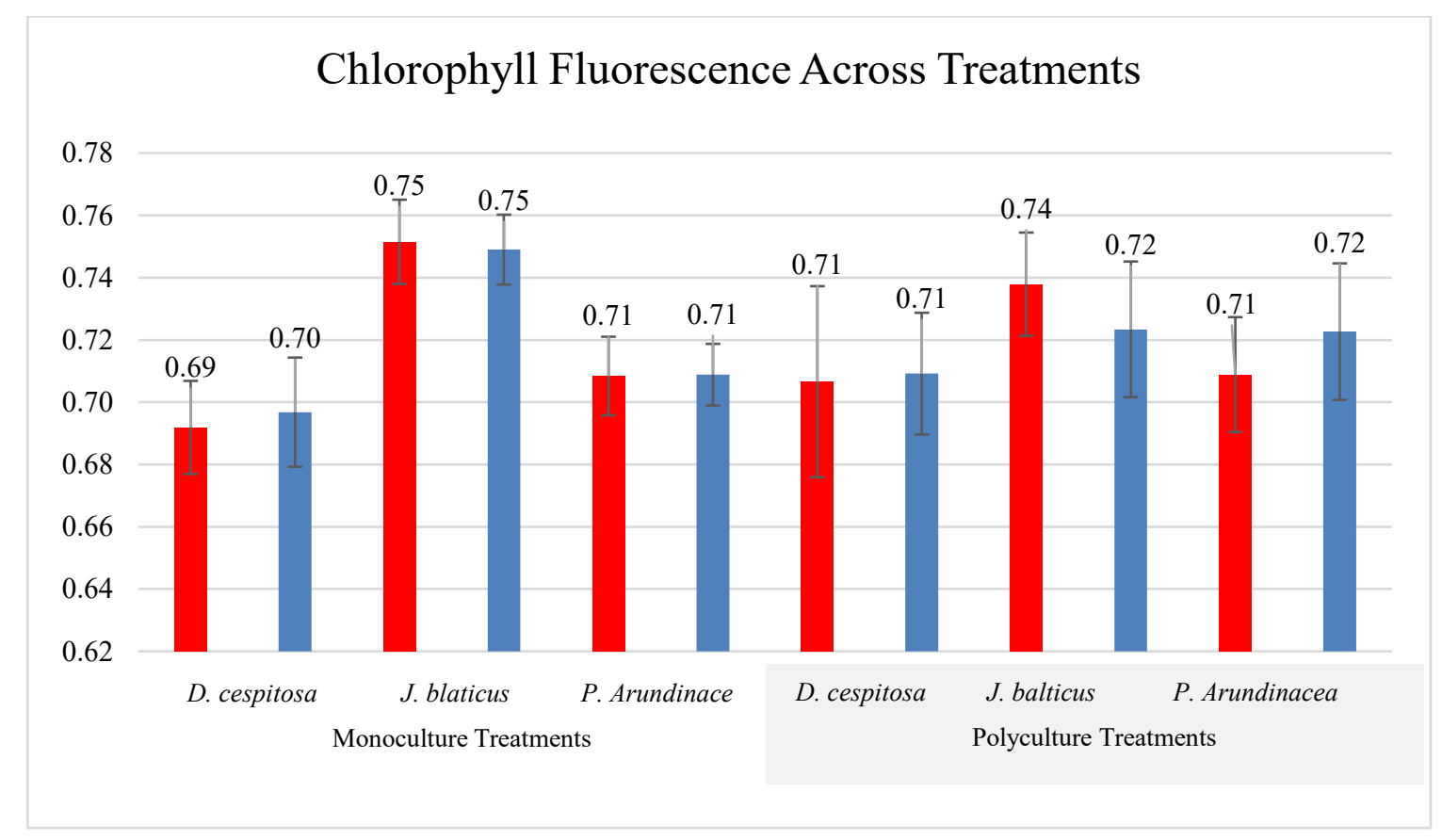

Figure 5. Chlorophyll Fluorescence Across all Treatments. Bar chart showing mean chlorophyll fluorescence (SD above bars) across the two community types (monoculture versus polyculture), three species, and AMF treatments. +AMF or -AMF treatments are indicated in red and blue, respectively. The averages of $J$. balticus seen in the polyculture treatment indicate differences between fungal treatments, and show decreased photosynthetic stress as measured in the PSII pathway when AMF inoculation is present.

\section{Summary Statistics Results}

Twenty-five replicates of each treatment survived through the entirety of the experiment, 10 variables were recorded after measurements and calculations, and there were 8 treatments across species, community, and fungi treatments (Table 5 below). Exploratory statistics (discussed below) demonstrated that all other 9 variables besides chlorophyll fluorescence were impacted or differentiated by the presence or absence of Fungi (+AMF or -AMF). The variables show potential differences between species $(D$. cespitosa, J. balticus, and P. arundinacea) and communities (Monoculture or Polyculture) while showing little difference between the fungal treatments (+AMF or -AMF). For 
example, canopy cover of $P$. arundinacea has the highest $\%$, is $4-5 \%$ greater in the monoculture, but differs by less than $0.5 \%$ between fungi treatments.

Table 5. Averages of all response variable across all treatments. $\mathrm{M}=$ Monoculture treatment, $\mathrm{P}=\mathrm{Polyculture}$ Treatment. $\mathrm{DECE}=$ D. cespitosa, $\mathrm{JUBA}=J$. Balticus, $\mathrm{PHAR}=P$. Arundinacea $. \mathrm{CHFL}=$ Chlorophyll fluorescence. $\mathrm{RCI}=$ Relative Competition Index, and represents the biomass as relative between culture trratments. No values can be used for the monoculture lines for the RCI: they are used to create the relative values to the polyculture lines.

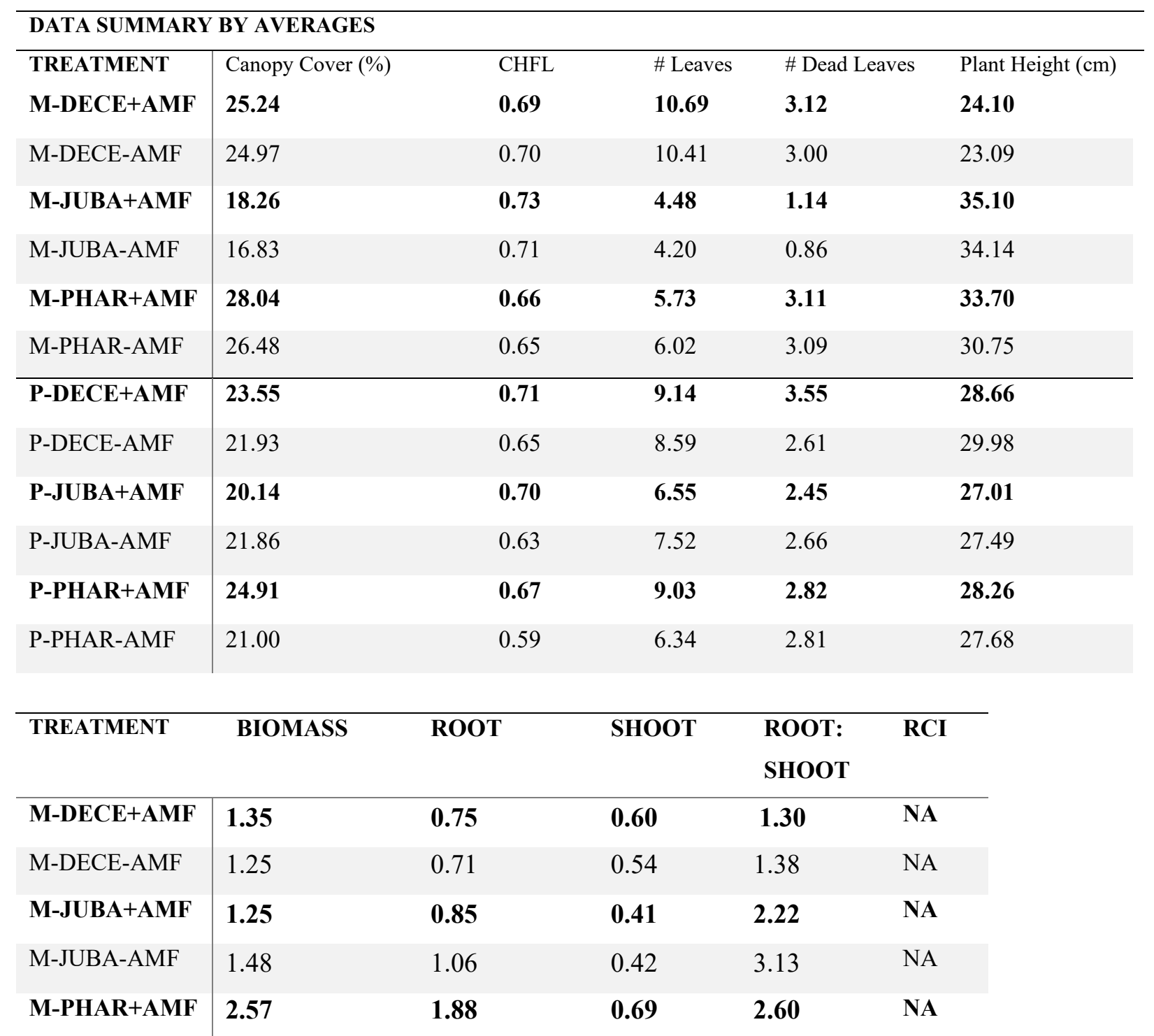




\begin{tabular}{l|lllll} 
M-PHAR-AMF & 2.25 & 1.63 & 0.62 & 2.68 & NA \\
\hline P-DECE+AMF & $\mathbf{1 . 5 4}$ & $\mathbf{0 . 9 5}$ & $\mathbf{0 . 5 9}$ & $\mathbf{1 . 7 2}$ & $\mathbf{- 1 . 4 9}$ \\
P-DECE-AMF & 1.74 & 1.12 & 0.62 & 2.06 & -2.24 \\
P-JUBA+AMF & $\mathbf{1 . 7 1}$ & $\mathbf{1 . 2 1}$ & $\mathbf{0 . 5 0}$ & $\mathbf{2 . 2 7}$ & $\mathbf{1 . 7 9}$ \\
P-JUBA-AMF & 1.16 & 0.75 & 0.41 & 1.85 & 3.37 \\
P-PHAR+AMF & $\mathbf{3 . 2 4}$ & $\mathbf{2 . 3 4}$ & $\mathbf{0 . 9 0}$ & $\mathbf{3 . 5 8}$ & $\mathbf{- 0 . 0 3}$ \\
P-PHAR-AMF & 2.77 & 1.97 & 0.80 & 2.43 & -2.11
\end{tabular}

A correlation matrix that included all variables showed high correlations among the variables related to biomass: roots, shoots, root:shoot ratios, and total biomass (Figure 5). All other variables had correlation values below 0.80 (after Feldman 185) and were considered non-covariate. Root weight was selected from this group of related variables to singularly represent biomass response variables to avoid the multicolinearity effect that using all four variables could cause. This variable was selected of the four due to its eigen value discussed in the subsequent PCA analysis results. 


\begin{tabular}{|c|c|c|c|c|c|c|c|}
\hline \multicolumn{8}{|c|}{ Correlation Matrix } \\
\hline $\begin{array}{l}\text { Chlorophyll } \\
\text { Fluorescence }\end{array}$ & & & & & & & \\
\hline-0.50 & $\begin{array}{l}\text { Number } \\
\text { of Dead } \\
\text { Leaves }\end{array}$ & & & & & & \\
\hline 0.31 & 0.52 & $\begin{array}{c}\text { Canopy } \\
\text { Cover } \\
(\%)\end{array}$ & & & & & \\
\hline-0.62 & 0.57 & 0.53 & $\begin{array}{l}\text { Number } \\
\text { of Live } \\
\text { Leaves }\end{array}$ & & & & \\
\hline 0.42 & 0.37 & 0.09 & 0.10 & $\begin{array}{c}\text { Plant } \\
\text { Height } \\
\text { (cm) }\end{array}$ & & & \\
\hline 0.14 & 0.10 & 0.56 & 0.13 & 0.41 & $\begin{array}{c}\text { Root } \\
\text { Weight (g) }\end{array}$ & & \\
\hline 0.16 & 0.11 & 0.66 & 0.58 & 0.25 & 0.69 & $\begin{array}{c}\text { Shoot } \\
\text { Weight (g) }\end{array}$ & \\
\hline 0.05 & 0.16 & 0.63 & 0.18 & 0.38 & 0.96 & 0.83 & $\begin{array}{c}\text { Total } \\
\text { Biomass } \\
\text { (g) }\end{array}$ \\
\hline
\end{tabular}

Figure 6. Correlation Matrix The correlation matrix demonstrates collinearity with a Spearman's rank correlation greater than 0.80 between root weight and biomass, and between shoot weight and biomass. Both Root weight and shoot weight are combined to measure total biomass, and thus their correlation is logical. All other variables have low correlations. 
Results from the PCA analysis revealed that all variables considered together did not account for variance within the dataset but that perhaps chlorophyll fluorescence, root weight, and canopy cover accounted for the most variance within the dataset. These results show that multivariate statistical tests would not be appropriate for this dataset. Eigen analysis showed that PC1 and PC2 were comprised of all variables, and each response variable accounted for a considerable proportion of the variance within their respective PC (Table 6).

Table 6. The eigen analysis quantified the loading of each relevant Principal Component (PC1 and PC2). The only positive eigenvector of $\mathrm{PC} 1$ was chlorophyll fluorescence. Canopy cover, and the related plant mass variables: root to shoot ratio, root weight, shoot weight, and biomass all showed the strongest negative accounting for variance within this dataset. This indicates that chlorophyll fluorescence is the largest positive predictors of that axis. PC2 is explained negatively by the root to shoot ratio, and positively by number of live leaves and chlorophyll fluorescence. These values were used to further explore this data, but the results yielded indication that no further analysis was appropriate.

Eigen Analysis Summary:

\begin{tabular}{|l|l|l|}
\hline \multicolumn{1}{|c|}{ Variable } & \multicolumn{1}{c|}{ PC1 } & \multicolumn{1}{c|}{ PC2 } \\
\hline Chlorophyll Fluorescence & 0.25 & 0.37 \\
\hline Number of Dead Leaves & -0.29 & -0.34 \\
\hline Canopy Cover & -0.42 & -0.11 \\
\hline Number of Live Leaves & -0.33 & -0.38 \\
\hline Height & -0.11 & 0.37 \\
\hline Shoot Weight & -0.40 & 0.37 \\
\hline Root Weight & -0.45 & 0.0 \\
\hline Biomass & -0.44 & 0.29 \\
\hline Root: Shoot Ratio & 0.48 & -0.61 \\
\hline
\end{tabular}


Root Colonization by Arbuscular Mycorrhizal Fungi Results:

It was not possible to achieve complete soil sterilization through $10 \%$ benomyl applications, but control treatments (-AMF) generally experience low levels of inoculation due to fungicide treatment. This demonstrates the vigorous nature of fungal inoculation despite sterilization techniques in greenhouse experiments. Percent root colonization assessment $(\mathrm{N}=120$ slide samples) confirmed that $+\mathrm{AMF}$ treatments were colonized, and -AMF treatments had low levels of colonization (Table 7).

Table 7. Percent of root colonization (\%) by AMF, arbuscules (\%), vesicles (\%), and hyphae (\%) seen in each treatment group. In culture, $\mathrm{MONO}=$ monoculture, POLY= polyculture. For Plant Species: $D$. cespitosa= Deschampsia cespitosa, J. balticus = Juncus balticus, and P. arundinacea $=$ Phalaris arundinacea. The total \% colonization does not necessarily equal the sum of all structures given that multiple structures may be found at each tally point.

Root Colonization by Arbuscular Mycorrhizal Fungi Summary

\begin{tabular}{|c|c|c|c|c|c|c|}
\hline \multirow[b]{2}{*}{ Culture } & \multirow[b]{2}{*}{$\begin{array}{c}\text { Plant } \\
\text { Species }\end{array}$} & \multicolumn{5}{|c|}{$\%$} \\
\hline & & $\begin{array}{c}\text { Fungal } \\
\text { Treatment }\end{array}$ & $\begin{array}{c}\text { \% Colonization } \\
\text { (STDV) }\end{array}$ & $\begin{array}{c}\text { Arbuscules } \\
\text { (STDV) }\end{array}$ & $\begin{array}{c}\text { \% Vesicles } \\
\text { (STDV) }\end{array}$ & $\begin{array}{c}\text { \% Hyphae } \\
\text { (STDV) }\end{array}$ \\
\hline Mono & D. cespitosa & $-\mathrm{AMF}$ & $12.6(3.1)$ & $5.5(2.8)$ & $5.2(2.2)$ & $11.6(3.1)$ \\
\hline Mono & D. cespitosa & $+\mathbf{A M F}$ & $45.8(8.7)$ & $17(5.5)$ & $13.8(4.9)$ & $34.3(6.9)$ \\
\hline Mono & J. balticus & $-\mathrm{AMF}$ & $7.1(1.6)$ & $2.4(1.2)$ & $3.6(2.9)$ & $6.7(1.7)$ \\
\hline Mono & J. balticus & $+\mathbf{A M F}$ & $33.9(3.7)$ & 33 (3.7) & $9.7(2.5)$ & $10.8(3.3)$ \\
\hline Mono & P. arundinacea & $-\mathrm{AMF}$ & $5.9(2.7)$ & $5.3(2.4)$ & $2.9(1.7)$ & $2.2(1.8)$ \\
\hline Mono & P. arundinacea & $+\mathbf{A M F}$ & $46.5(13)$ & $43.2(12.5)$ & $15.6(5.4)$ & $29.1(9.5)$ \\
\hline Poly & D. cespitosa & $-\mathrm{AMF}$ & $8.3(3.5)$ & $6.9(3.1)$ & $4.1(2.7)$ & $3.4(3.5)$ \\
\hline Poly & D. cespitosa & $+\mathbf{A M F}$ & $33.3(3.3)$ & $6.7(3.6)$ & $13.2(4.1)$ & $30.3(4.1)$ \\
\hline Poly & J. balticus & $-\mathrm{AMF}$ & $6(2.1)$ & $1.5(.9)$ & $2.3(1.4)$ & $5.6(1.9)$ \\
\hline Poly & J. balticus & $+\mathbf{A M F}$ & $12.2(3.9)$ & $3.9(2)$ & $6.2(2.3)$ & $11(4.1)$ \\
\hline Poly & P. arundinacea & $-\mathrm{AMF}$ & $5.7(2.6)$ & $4.8(1.9)$ & $2.8(1.7)$ & $0.9(0.8)$ \\
\hline Poly & P. arundinacea & $+\mathbf{A M F}$ & $30.2(6.7)$ & $8.1(4.6)$ & $14.6(5.9)$ & $27.5(6)$ \\
\hline
\end{tabular}


Chapter 2: Experiment Discussion

AMF impacts to plant communities can be highly context dependent, as is demonstrated by the interaction among fungal treatment type, community type, and plant species. Additionally, differences in chlorophyll fluorescence between fungal treatments of $J$. balticus roots with or without fungi show the potential for AMF to alter individual plant health. In this experiment a species-specific result showed that AMF collected from native marsh soil provided more stress relief for the native $J$. balticus than $P$. arundinacea, a known problematic invasive grass. These species-specific effects of AMF may in turn impact the make-up of plant community structure in salt marshes, particularly the high marsh.

It was hypothesized that plants with AMF would express their competition strategies differently when grown in a community because this context would exemplify interspecific competition, whereas the monocultures exemplify intraspecific competition. To examine the effect of AMF on the competition strategies of three salt marsh plant species, ten response variables were measured in both monocultures and polycultures, with and without $\mathrm{AMF}$ inoculation (+AMF or $-\mathrm{AMF}$, respectively). Results for chlorophyll fluorescence, which measures plant stress through its photosynthetic pathway II, when concerning J. balticus with or without fungus in the polyculture treatment, showed differences in the way plants expressed their competitive strategy with a relative difference in plant stress tolerance. The other 9 variables that are associated with the way plants assimilate and allocate physical mass (root: shoot ratios and plant biomass), demonstrated similar means between the two AMF treatments and so were not evaluated 
with factorial ANOVA. The data showing high similarity between the $+\mathrm{AMF}$ and $-\mathrm{AMF}$ treatments for the 9 other response variables (Table 2, Appendix 1) did not directly support the hypothesis that competition strategy expression would be exacerbated in the polyculture.

The differing nature of each study species' competition strategies, association with $\mathrm{AMF}$, and persistence across landscapes globally makes for uniquely interesting comparisons amongst the family of graminoid plants, Poaceae, that typically dominate salt marsh systems. It was also hypothesized that each of the three species examined will demonstrate different levels of AMF inoculation/colonization in their plant roots. These levels of colonization also varied by species, which indicates that each species does indeed have their own level of symbiosis and that these growth levels were demonstrated during the early stages of their life histories.

Juncus balticus, a native plant that occurs commonly in freshwater systems, is not known to frequently associate with AMF, and thus was not expected to be greatly affected by AMF inoculation, or lack thereof. This slower growing plant does not immediately compete well for space, and instead invests energy into producing high volumes of small seeds that locally disperse. This plant also has a rapid regrowth response to browsing and physical disturbance in freshwater systems (Mårtensson 2017). In this study J. balticus was predicted to show a stress tolerant or ruderal response given its lack of competition for resource success shown by Larkin et al. 2012, which would be supported by actual confirmation that this species experiences reduced stress when inoculated by AMF when grown in a polyculture community. This study does indeed observe this and shows that 
differences between $+\mathrm{AMF}$ and $-\mathrm{AMF}$ in the polyculture during the shorter duration of this study (Figure 5, Table 4) were noticeable. This finding might be expanded upon by future experiments with longer timelines that may be fruitful in demonstrating the nature of this phenomenon. Field study in salt marshes that examines J. balticus chlorophyll fluorescence, with +AMF and -AMF treatments in may also support the idea that AMF reduces physiological stress of this species when grown in a stressful environment.

Phalaris arundinacea was expected to have a significant response to inoculation as it is known to associate with AMF and frequently demonstrates high levels of inoculation in freshwater wetlands (Boutton 2019). This plant's success in invading wetlands around the world has been widely documented, and is attributed to its prolific acquisition of nitrogen, and rapid root development that dominates surrounding soil area (Lavergne and Molosky 2004). While there was confirmed inoculation, +AMF in monocultures did not show differences in any of the response variables, although differences in chlorophyll fluorescence can be seen in $P$. arundinacea grown in polycultures between +AMF and AMF can be seen (Figure 5). This trend, however, was not statistically supported by the Tukey HSD test. If $P$. arundinacea demonstrated differences akin to the trends seen here, it would mean that AMF inoculation decreased the plant's abilities to mitigate stress from the environment, which is shown by the $+\mathrm{AMF}$ treatment having the lower average chlorophyll fluorescence compared to -AMF treatments.

Deschampsia cespitosa, a widespread native bunchgrass in Oregon wetlands and around the world, is known to associate with AMF and is known to benefit from a fungal symbiont upon successful inoculation in freshwater systems contaminated with heavy 
metals (Davy et al. 2019). While this species experienced inoculation in the greenhouse, it did not demonstrate differences in competition when measurements were compared between $+\mathrm{AMF}$ and $-\mathrm{AMF}$ treatments across all 10 measured response variables. The chlorophyll fluorescence measurements visually look slightly higher in polyculture compared to monoculture communities but did not significantly differ (posthoc $p>>0.05$ ). These results show that AMF does not impact this species in this context as seen by any of the three independent grouping variables. This plant may ultimately not compete differently in the presence of fungal symbionts when growing in salt marshes and may instead associate with fungi due to evolution of symbiosis which in this context forms neither a helpful symbiont nor parasitic symbiont.

Across all three species, there were no visual trends or statistically significant differences between AMF treatments in monocultures. The only near differences, previously discussed in relation to $J$. balticus and $P$. arundinacea, presented themselves in the polyculture community type. Future work that explored this possible difference may provide interesting insight about whether AMF mediate interactions differently between intra- versus interspecific species within a salt marsh community. A neighbor removal study that examined 5 freshwater wetland species revealed several species-specific neighboring effects that were driven by AMF and varied between facultative and competitive interactions based on plant identity and dominant or subdominant establishment (Zhang et al. 2013). Additionally, another study in a freshwater system demonstrated the effects of AMF on size inequities on intraspecific communities (Ayres et al. 2006). In environments containing brackish water the differences in habitat type may 
parallel freshwater systems but may also be altered by the presence of salt stress that is mitigated differently by plant species (Liancourt et al. 2005). In salt marshes AMF effects may impact both intra- and interspecific interactions, but this study suggests the interspecies interactions may be more pronounced in the specific interactions seen here between D. cespitose, J. balticus, and P. arundinacea.

Chlorophyll fluorescence measures document the photosynthetic response of a plant as seen in the PSII pathway, more specifically a "photosynthetic quenching" response (Maxwell and Johnson 2000). Differing chlorophyll fluorescence values in $P$. arundinacea with and without AMF inoculation could indicate that this species may be responding to environmental stresses in the presence or absence of AMF. The greenhouse conditions were modelled after the reference marsh in Salmon River, OR, and thus the argument can be made that stress responses of $P$. arundinacea with AMF may differ in natural conditions as well. Results from the Tukey HSD test $(\mathrm{p}=0.35)$, and visuals depicted in Figure 3 show that $P$. arundinacea may have higher stress in its PSII pathway system in the presence of AMF, which may show that AMF parasitizes the non-native species in this context. If this invasive plant experiences higher stress with fungal symbionts in natural conditions, it can be expected to decline under continued stressful marsh conditions, and potentially under the additional stressors predicted to occur under climate change conditions. This decline could benefit mixed native plant communities that ultimately do not outcompete this highly invasive plant in competition for nutrient resources. This species has been seen to alter wetland and salt marsh function greatly, with differing effects across plants, animals, and abiotic processes (Annen et al 2008, Barnes 
1999, Spyreas et al. 2010) and remain of interest to land managers in all PNW wetland habitats.

It is interesting however, that none of the other growth metrics measured appeared to have differences between inoculated and non-inoculated treatments and were eliminated from further testing during preliminary data exploration. Consideration of the short timeline under which this experiment occurred may give insight to this observation. In order to circumvent pot edge effects on root systems, the experiment was ended 70 days after the first measurement. This represents the juvenile life stage of the study species. Each of these species may benefit from fungal symbionts at different times in their lives. For example, a plant with rapid biomass expansion due to resource exploitation as an adaptive strategy (Competitor strategy) may benefit from early colonization from AMF whereas a plant that responds rapidly to browsing and disturbance events may benefit from long-term sustained colonization by AMF (Ruderal strategy) as theorized by Grimes 1979. At these times various growth variables and additional measurement of reproductive material assimilation may be more impacted by AMF treatments.

It may well be that the variables measuring competition did not vary strongly with AMF treatment or culture setting because the experiment ended too soon for these variables to be strongly affected by those factors. Chlorophyll fluorescence may be a metric that shows early or throughout a plant's life, whereas differences in biomass distribution may occur later in the life history of long-lived grasses such as those involved in this experiment. Hence, future work could include experiments over a longer duration, which would require larger pots, and perhaps transplanting of older plants instead of 
transplanting seedlings 1-2 weeks after germination. This would better observe the effects of AMF on these species during juvenile and reproductive life stages. Additional field experiments that apply $10 \%$ Benomyl solution to eliminate fungi within plots across different populations of gramminoids, which include both native and non-native species, would better study competition expression directly in the study system, the salt marsh. These field studies could occur at different elevations within a study marsh and could include water regime alteration treatments to mimic sea level rise under different predicted climate change conditions. Future work could also explore AMF effects of high marsh plant stock used for restoration. It is becoming easier for native plant nurseries to apply commercial inoculants containing AMF and additional rhizobia across many soil microbe taxa to their plant stock in hopes of bolstering plant health through symbiont benefits. These additions could aid J. balticus more than natives in some situations and is worthy of consideration by applied scientists responsible for land management of native plant communities.

Overall AMF was shown to change alter stress tolerance as a competition strategy between the three salt marsh plants examined here. The data suggest that AMF may impact $J$. balticus and $P$. arundinacea inversely in their stress response, but only when grown in a mixed community. AMF may decrease the physiological stress of J. balticus plants, and increase stress seen in P. arundinacea, which may overall aid in the growth and success of one native plant over a highly invasive non-native plant. This may occur due to a variety of mechanisms, each of which would require further study, but ultimately suggest that the AMF native to the reference marsh may evoke proliferation of native 
species. It is unknown how intentional fungal inoculation affects plant competition in salt marshes, which are dominated by herbaceous plants. Introduction of nonnative AMF communities may impact regional land management efforts that recently have begun to consider inoculation of native plants when restoring salt marshes, to better ensure planting survival. These inoculation treatments currently do not target site-specific fungal communities, but instead primarily are composed of species most beneficial to agricultural crops. If native AMF are used to inoculate their respective native plant community, and show greater benefits to native plants over non-native plants, these inoculant treatments could improve the overall survival and success of native plantings, and will increase the associated functionality that these plants provide. Conversely, commercial inoculants that do not contain AMF sources from a given site, unique habitat or specific location may not benefit native plants in the same way. These globally common fungi may form unforeseen, potentially helpful relationships with globally successful invasive plants such as $P$. arundinacea. The effects of commercial inoculants on native and non-native plant communities will require further research, and current restoration efforts may do well to practice caution in their use. Blind investment in commercial inoculants seeking to bolster the survival of native plants may be counterproductive and should be approached with reserve given limited nature of restoration project capacity (both logistical and financial limitations are to be considered here). "Limited restoration funds might be more efficiently spent on diverse plant stocks, inoculating with native soil that already contains site-specific microbial communities, and monitoring. 
Chapter 3: Study Conclusions

This work sought to observe how different plants responded through secondary competition to AMF inoculation in a uniquely stressful loving environment. Much work to date has focused on plant individuals and community responses to AMF, which has led to the general understandings that in exchange for photosynthetic byproducts these fungi can benefit their symbiotic hosts when nutrients or water are limited, and can offer stress or predation amelioration. However, within salt marsh systems such as the reference marsh used in this research, it was hypothesized that the symbiotic relationship between AMF its three host plants might express itself differently due to the stronger presence of stress as an ecosystem driver. It was specifically hypothesized that any changes in this relationship would be most pronounced and impactful when examined in a small community of plants dominate the high marsh landscape, where stress amelioration would be the most impactful. AMF was specifically shown to impact plants in a three-way interaction between AMF treatment, community type, and species, with a stress relief effect seen in one of the native plants, J. balticus, when it was inoculated with fungi.

To examine plant responses to AMF inoculation while under physiological stress a common greenhouse experiment was conducted to closely measure 10 response variables in the absence of environmental variability. This was done by exposing all plants to homogeneous environmental conditions, and only altering whether plants were inoculated with AMF. After the experiment ended, data were first explored through multivariate statistical analyses, but it was found that most of the measured response variables contributed little to explaining variance within the dataset. The subsequent univariate 
analysis revealed that being grown in a mixed community, specific plant species, and AMF inoculation or lack thereof had a three-way effect on the chlorophyll fluorescence, a stress measure, levels within plant leaves. Additionally, chlorophyll fluorescence differed significantly between Juncus balticus plants with or without AMF inoculation, but only when this plant was grown in a mixed community as opposed to when it was grown with other J. Balticus plants. This effect was $P$. arundinacea showed a near significant effect of chlorophyll fluorescence,

This work shows the importance of considering which species of plants may forms symbiotic relationships with site specific fungi, and how that relationship may affect plant interactions. The results of such interactions could alter the composition of plant communities and may be used to assess land management practices in the future. The identities of the AMF in the Salmon River estuary were not revealed in this work but future investigation of AMF species present that would require DNA sequencing or morphological identification to understand the diversity and abundance of present AMF species, could give further insight to the nature of these relationships. The use of DNA sequencing to identify fungal species would lead to better taxonomic documentation, and would release pressure from the highly specialized field of visual morphological identification, which currently creates a bottleneck around the amount of data that can be collected about various AMF species. It would be particularly important to understand whether the AMF present were locally endemic, globally common, or some mixture of the two. If AMF species were globally abundance then use of commercial inoculants would be potentially less problematic, and more research would be likely to focus on these 
species and lend insight to the system. If AMF species present at the Salmon River site were locally endemic, then perhaps the native plants would have more closely evolved to form relationships with these species. This would mean that the introduction of globally abundance species, by the use commercial inoculants for instance, could benefit nonnative plants that are better suited to form symbiotic relationships with fungi from afar. Additionally, using equipment from other parts of the world could introduce foreign fungal species can cause similar unintentional introductions. 


\section{Literature Cited}

Aggarwal, A., Kadian, N., Tanwar, A., \& Gupta, K. K. (2012). Arbuscular mycorrhizal symbiosis and alleviation of salinity stress, $144-155$.

Annen C. A., Kirsch E. M., Tyser R. W. (2008) Reed canary grass invasions alter succession patterns and may reduce habitat quality in wet meadows. Ecological Restoration 26:190-193

Ayres R. L., Gange A. C., and Aplin D. M., (2006). Interactions between arbuscular mycorrhizal fungi and intraspecific competition affect size, and size inequality, of Plantago lanceolata $\mathrm{L}$, Journal of Ecology, 94(2). 285-294.

Barnes W. J. (1999) The rapid growth of a population of reed canary grass (Phalaris arundinacea L.) and its impact on some river bottom herbs. J Torrey Botanical Society, 126: 133-138

Bauer, C. R., Kellogg, C. H., Bridgham, S. D., \& Lamberti, G. A. (2003). Mycorrhizal Colonization Across Hydrologic gradients in Restored and Reference Freshwater Wetlands. Wetlands, 23(4), 961-968. https://doi.org/10.1672/0277-5212(2003)023

Bernard, J. M., Solander, D., \& Květ, J. (1988). Production and nutrient dynamics in Carex wetlands. Aquatic Botany, 30, 125-147. https://doi.org/10.1016/0304-3770(88)90011-3

Bertness, M.D. \& Ellison, A.M. (1987) Determinants of pattern in a New England salt marsh plant community. Ecological Monographs, 57, 129-147.

Bertness, M.D., Hacker, S.D. (1994). Physical Stress and Positive Associations Among Marsh Plants. The American Society of Naturalists, 144(3), 363-372

Borchert, S. M., Griffith, K. T., Osland, M. J., \& Enwright, N. M. (2018). Coastal wetland adaptation to sea level rise: Quantifying potential for landward migration and coastal squeeze, (March), 2876-2887. https://doi.org/10.1111/1365-2664.13169

Boutton, T.W., Harrison, A.T., Smith, B.N., Boutton, T.W., Harrison, A.T., \& Smith, B.N. (2019). International Association for Ecology Distribution of Biomass of Species Differing in Photosynthetic Pathway along an Altitudinal Transect in Southeastern Wyoming Grassland 
Published by: Springer in cooperation with International Association for Ecology.

Https://www.jstor.org/stable/4216095, 45(3), 287-298.

Brown, C.A. and R.J. Ozretich. 2009. Coupling between the coastal ocean and Yaquina Bay, Oregon: Importance of oceanic inputs relative to other nitrogen sources. Estuaries and Coasts 32: 219-237.

Burke, D. J., Hamerlynck, E. P., \& Hahn, D. (2002). Effect of arbuscular mycorrhizae on soil microbial populations and associated plant performance of the salt marsh grass Spartina patens. Plant and Soil, 239, 141-154.

Carvalho, L., \& Caçador, I. (2001). Temporal and spatial variation of arbuscular mycorrhizas in salt marsh plants of the Tagus estuary (Portugal). Mycorrhiza, (11), 303-309.

https://doi.org/10.1007/s00572-001-0137-6 Canepuccia, A. D., Pérez, C. F., \& Farina, J. L. (2013). Dissimilarity in plant species diversity between salt marsh and neighboring environments decreases as environmental harshness increases, (December). https://doi.org/10.3354/meps10556

Cendrero-Mateo, M., Carmo-Silva, A., Porcar-Castell, A., Hamerlynck, E., Papuga, S., \& Moran, M. (2015). Dynamic response of plant chlorophyll fluorescence to light, water and nutrient availability. Functional Plant Biology, 42(8), 746-757.

Crosby, S. C., Sax, D. F., Palmer, M. E., Booth, H. S., Deegan, L. A., Bertness, M. D., \& Leslie, H. M. (2016). Estuarine, Coastal and Shelf Science Salt marsh persistence is threatened by predicted sea-level rise. Estuarine, Coastal and Shelf Science, 181, 93-99.

https://doi.org/10.1016/j.ecss.2016.08.018

Costanza, R., R. de Groot, P. Sutton, S. van der Ploeg, S. J. Anderson, I. Kubiszewski, S. Farber, and R. K. Turner. 2014. Changes in the global value of ecosystem services. Global Environmental Change 26:152-158.

Davy, A. A. J. (2019). Deschampsia Caespitosa (L.) Beauv. Published by British Ecological Society. Https://www.jstor.org/stable/2259475, 68(3), 1075-1096.

Diefenderfer, H. L., Sinks, I. A., Zimmerman, S. A., Cullinan, V. I., \& Borde, A. B. (2018). Designing topographic heterogeneity for tidal wetland restoration. Ecological Engineering, 123(September), 212-225. https://doi.org/10.1016/j.ecoleng.2018.07.027 
Eilers, H. P. (1979). Production ecology in an Oregon coastal salt marsh. Estuarine and Coastal Marine Science, 8(5), 399-410. https://doi.org/10.1016/0302-3524(79)90057-4

Ewing, K. Plant growth and productivity along complex gradients in a Pacific northwest brackish intertidal marsh. Estuaries 9, 49-62 (1986). https://doi.org/10.2307/1352193

Feldman S. Berry, Multiple Regression in Practice (Quantitative Applications in the Social Sciences) SAGE Publications; Thousand Oaks. CA: 1985.

Fraser, L. H., \& Feinstein, L. M. (2005). Effects of mycorrhizal inoculant, N:P supply ratio, and water depth on the growth and biomass allocation of three wetland plant species. Canadian Journal of Botany, 83(9), 1117-1125. https://doi.org/10.1139/b05-084

Frenkel, R. E., \& Morlant, J. C. (1993). Can we restore our salt marshes? Lessons from the Salmon River, Oregon. Biological Conservation, 63(1), 104. https://doi.org/10.1016/00063207(93)90124-J

Gaudet, C. L., \& Keddy, P. A. (1995). Competitive Performance and Species Distribution in Shoreline Plant Communities: A. Source: Ecology (Vol. 76).

Gray, A., Simenstad, C. A., Bottom, D. L., \& Cornwell, T. J. (2002). Contrasting functional performance of juvenile salmon habitat in recovering wetlands of the Salmon River estuary, Oregon, U.S.A. Restoration Ecology, 10(3), 514-526. https://doi.org/10.1046/j.1526100X.2002.01039.x

Grime, J.P. (1979) Plant Strategies and Vegetation Processes. John Wiley and Sons, New York, NY.

Grime, J. Philip, et al. Comparative Plant Ecology: A Functional Approach to Common British Species. Castlepoint Press, 2007.

Hoeksema, J. D., Chaudhary, V. B., Gehring, C. A., Johnson, N. C., Karst, J., Koide, R. T., Umbanhowar, J. (2010). A meta-analysis of context-dependency in plant response to inoculation with mycorrhizal fungi. Ecology Letters, 13(3), 394-407. https://doi.org/10.1111/j.14610248.2009.01430.x 
Hurd, E.G., N.L. Shaw, and L.C. Smithman. 1992. Cyperaceae and Juncaceae -- selected lowelevation species. Proceedings of Symposium on Ecology, Management, and Restoration of Intermountain Annual Rangelands, Boise, ID. May 18-22, 1992. p.380-383.

Ingham, E. R., \& Wilson, M. V. (1999). The mycorrhizal colonization of six wetland plant species at sites differing in land use history. Mycorrhiza. https://doi.org/10.1007/s005720050272

Katschnig, D., Broekman, R., \& Rozema, J. (2013). Salt tolerance in the halophyte Salicornia dolichostachya Moss: Growth, morphology, and physiology. Environmental and Experimental Botany, 92, 32-42. https://doi.org/10.1016/j.envexpbot.2012.04.002

Keammerer, H. B. (2011). Community Structure, Plant Interactions, Seedling Performance and Seed Bank Compositions of Salt Marshes along an Estuarine Gradient in Coos Bay, Oregon.

Larkin, D. J., Lishawa, S. C., \& Tuchman, N. C. (2012). Appropriation of nitrogen by the invasive cattail Typha $\times$ glauca. Aquatic Botany, 100, 62-66. https://doi.org/10.1016/j.aquabot.2012.03.001

Lavergne, S., \& Molofsky, J. (2004). Reed Canary Grass (Phalaris arundinacea) as a Biological Model in the Study of Reed Canary Grass (Phalaris arundinacea) as a Biological Model in the Study of Plant Invasions. Critical Reviews in Plant Sciences, 23(5), 415-429.

https://doi.org/10.1080/07352680490505934

P. Liancourt, E. Corcket, and R. Michalet, (2005). Stress tolerance abil- ities and competitive responses in a watering and fertilization field experiment, Journal of Vegetation Science, vol.16, 6, pp.713-722,2005.

Levine, J. M., Brewert, J. S., \& Bertness, M. D. (2019). Nutrients, Competition and Plant Zonation in a New England Salt Marsh Author (s): Jonathan M. Levine, J. Stephen Brewer and Mark D. Bertness Published by: British Ecological Society Stable URL:

https://www.jstor.org/stable/2648552 Nutrients, competition and plant zonation in a New England salt marsh, 86(2), 285-292.

Lin, G., Mccormack, M. L., \& Guo, D. (2015). Arbuscular mycorrhizal fungal effects on plant competition and community structure. Journal of Ecology. https://doi.org/10.1111/1365-

2745.12429 
Odum, W. E. (1988). Comparative Ecology of Tidal Freshwater and Salt Marshes. Annual Review of Ecology and Systematics, 19, 147-176. Retrieved from

https://www.jstor.org/stable/2097151\%0D

Olsson, P. A., Postma, J., \& Falkengren-grerup, U. (2008). Soil Biology \& Biochemistry

Colonization by arbuscular mycorrhizal and fine endophytic fungi in four woodland grasses variation in relation to $\mathrm{pH}$ and aluminium, 40, 2260-2265.

https://doi.org/10.1016/j.soilbio.2008.05.002

Mårtensson, L., Carlsson, G., Prade, T., Kørup, K., Erik, P., \& Steen, E. (2017). Plant Physiology and Biochemistry Water use efficiency and shoot biomass production under water limitation is negatively correlated to the discrimination against $13 \mathrm{C}$ in the $\mathrm{C} 3$ grasses Dactylis glomerata, Festuca arundinacea and Phalaris arundinacea. Plant Physiology et Biochemistry, 113, 1-5. https://doi.org/10.1016/j.plaphy.2017.01.021

Martina, J. P., \& von Ende, C. N. (2013). Increased spatial dominance in high nitrogen, saturated soil due to clonal architecture plasticity of the invasive wetland plant, Phalaris arundinacea. Plant Ecology, 214(12), 1443-1453. https://doi.org/10.1007/s11258-013-0265-z

Maxwell, K., \& Johnson, G. N. (2000). Chlorophyll fluorescence - a practical guide, 51(345), 659-668.

McHugh, J. M., \& Dighton, J. (2004). Influence of Mycorrhizal Inoculation, Inundation Period, Salinity, and Phosphorus Availability on the Growth of Two Salt Marsh Grasses, Spartina alterniflora Lois. and Spartina cynosuroides (L.) Roth., in Nursery Systems, 12(4), 533-545.

Nelson J.L., Zavaleta E.S. (2012) Salt Marsh as a Coastal Filter for the Oceans: Changes in Function with Experimental Increases in Nitrogen Loading and Sea-Level Rise. PLoS ONE 7(8): e38558. doi: 10.1371/journal.pone.0038558

Peay, K. G., Kennedy, P. G., \& Bruns, T. D. (2008). Fungal Community Ecology: Bioscience, 58(9), 799-810.

Pine, S. (2018). Desktop Plant Stress Guide: Edition 5.1 - 04/15/18 
Raposa B. Kenneth, Kerstin Wasson, Erik Smith C., Jeffrey A. Crooks d, Patricia Delgado e, S. H. F. f, \& Matthew C. Ferner g, Alicia Helms h, LyndieA.Hice i, Jordan W. Mora j, Brandon Puckett k, Denise Sanger 1, Suzanne Shull m, Lindsay Spurrier n, Lerberg, S., R. S. (2013). Assessing tidal marsh resilience to sea-level rise at broad geographic scales with multi-metric indices. Biological Conservation, 204, 263-275. https://doi.org/10.1016/j.biocon.2016.10.015

Seliskar, M. Denise, Gallagher. L. John. (1983). The Ecology of Tidal Marshes of the Pacific Northwest Coast: A Community Profile. Philosophical Transactions of the Royal Society B:

Biological Sciences, 356(1408), 421-435. https://doi.org/10.1098/rstb.2000.0775

Seliskar, D. M. (2019). Morphometric Variations of Five Tidal Marsh Halophytes Along Environmental Gradients Author (s): Denise M. Seliskar Published by: Wiley Stable URL: https://www.jstor.org/stable/2443506, 72(9), 1340-1352.

Sparks, Donald L. Methods of Soil Analysis. Vol. 3, Soil Science Society of America, 2009.

Spyreas, G., Wilm, Æ. B. W., Plocher, Æ. A. E., Ketzner, D. M., Matthews, Æ. J. W., Ellis, J. L., $\&$ Heske, Æ. E. J. (2010). Biological consequences of invasion by reed canary grass (Phalaris arundinacea). Biological Invasions, 12, 1253-1267. https://doi.org/10.1007/s10530-009-9544-y

Stohlgren, Thomas J. Measuring Plant Diversity Lessons from the Field. Oxford University Press, 2007.

Tadych, M., \& Blaszkowski, J. (2014). Growth responses of maritime sand dune plant species to arbuscular mycorrhizal fungi, (September). https://doi.org/10.5586/am.1999.010

Torio, D.D., and G.L. Chmura. 2013. Assessing coastal squeeze of tidal wetlands. Journal of Coastal Research 29: 1049-1061.

Wang, Y., Li, Y., Bao, X., Björn, L. O., Li, S., \& Olsson, P. A. (2016). Response differences of arbuscular mycorrhizal fungi communities in the roots of an aquatic and a semiaquatic species to various flooding regimes. Plant and Soil, 403(1-2), 361-373. https://doi.org/10.1007/s11104-0162811-7

Weigelt, A., \& Jolliffe, P. (2003). Indices of plant competition, 707-720. 
Weis J. S., Segarra K. E. A., P. B. (2016). Chapter 50: Salt Marshes. The Intergovernmental Panel on Climate Change (IPCC), Chapter 50, 1-9.

Weller, M. W. 1994. Bird-habitat relationships in a Texas estuarine marsh during summer.

Wetlands 14:293-300

Wilde, P., Manal, A., Stodden, M., Sieverding, E., Hildebrandt, U., \& Bothe, H. (2009).

Biodiversity of arbuscular mycorrhizal fungi in roots and soils of two salt marshes. Environmental Microbiology. https://doi.org/10.1111/j.1462-2920.2009.01882.x

Zhang, Q., Sun, Q., Koide, R. T., Peng, Z., Zhou, J., Gu, X., Yu, M. (2014). Arbuscular

mycorrhizal fungal mediation of plant-plant interactions in a marshland plant community. The Scientific World Journal, 2014. https://doi.org/10.1155/2014/923610 


\section{Appendix A. Additional Figures}
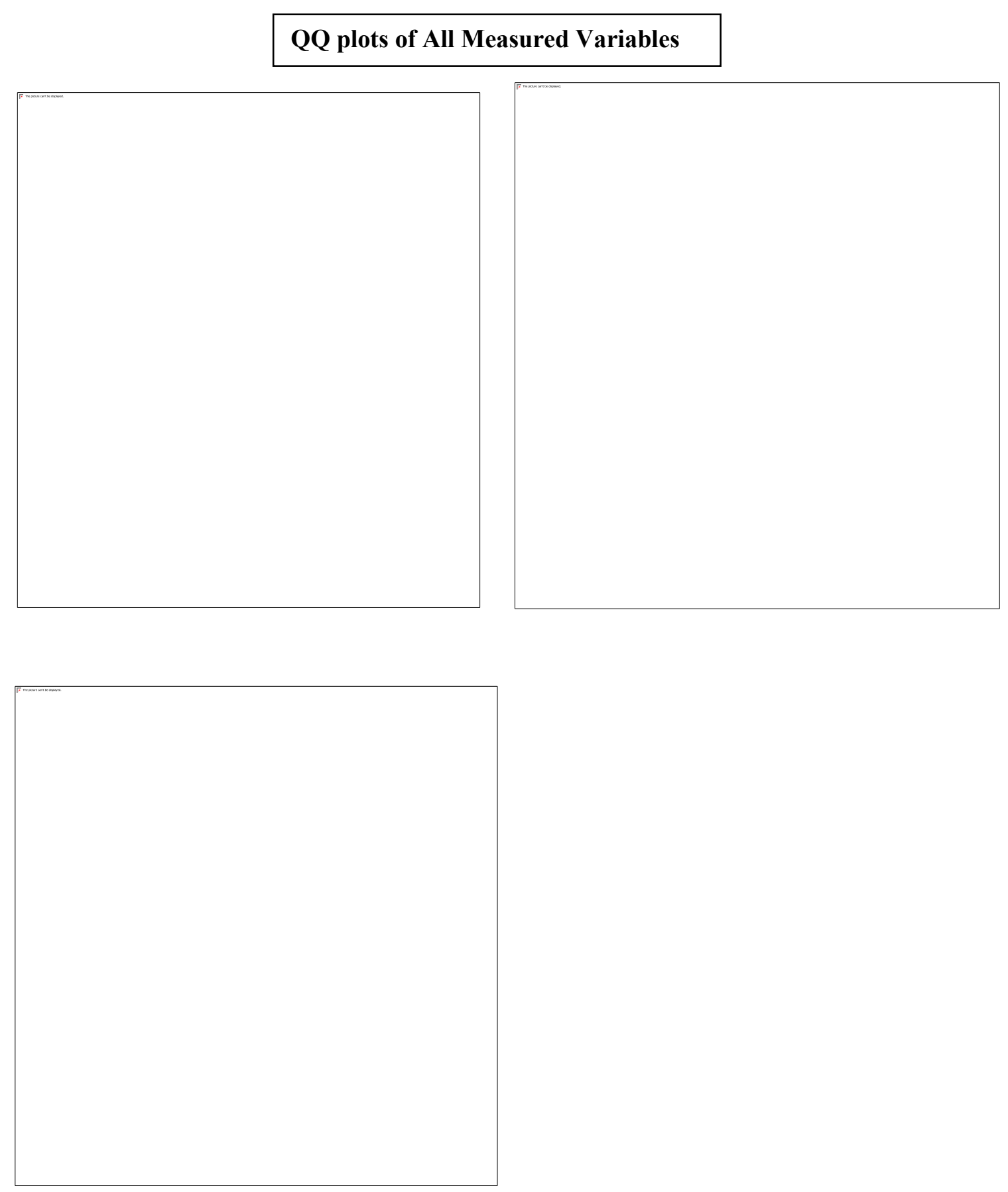

Figure 7. QQ plots of all variables initially considered in this data set. 
QQ plots of All Measured Variables
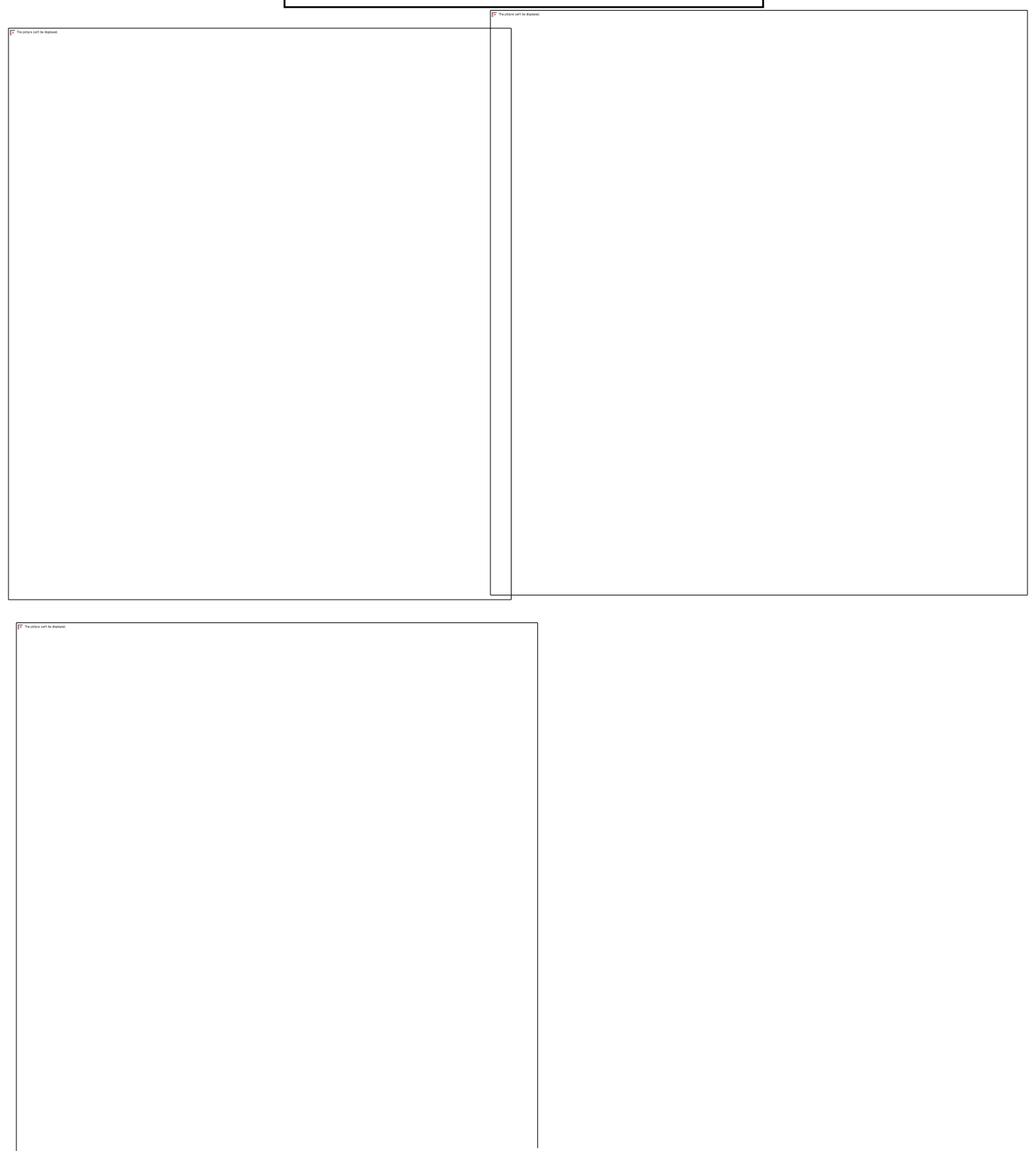

Figure 7. All Variables' QQ plots, continued. 
QQ plots of All Measured Variables
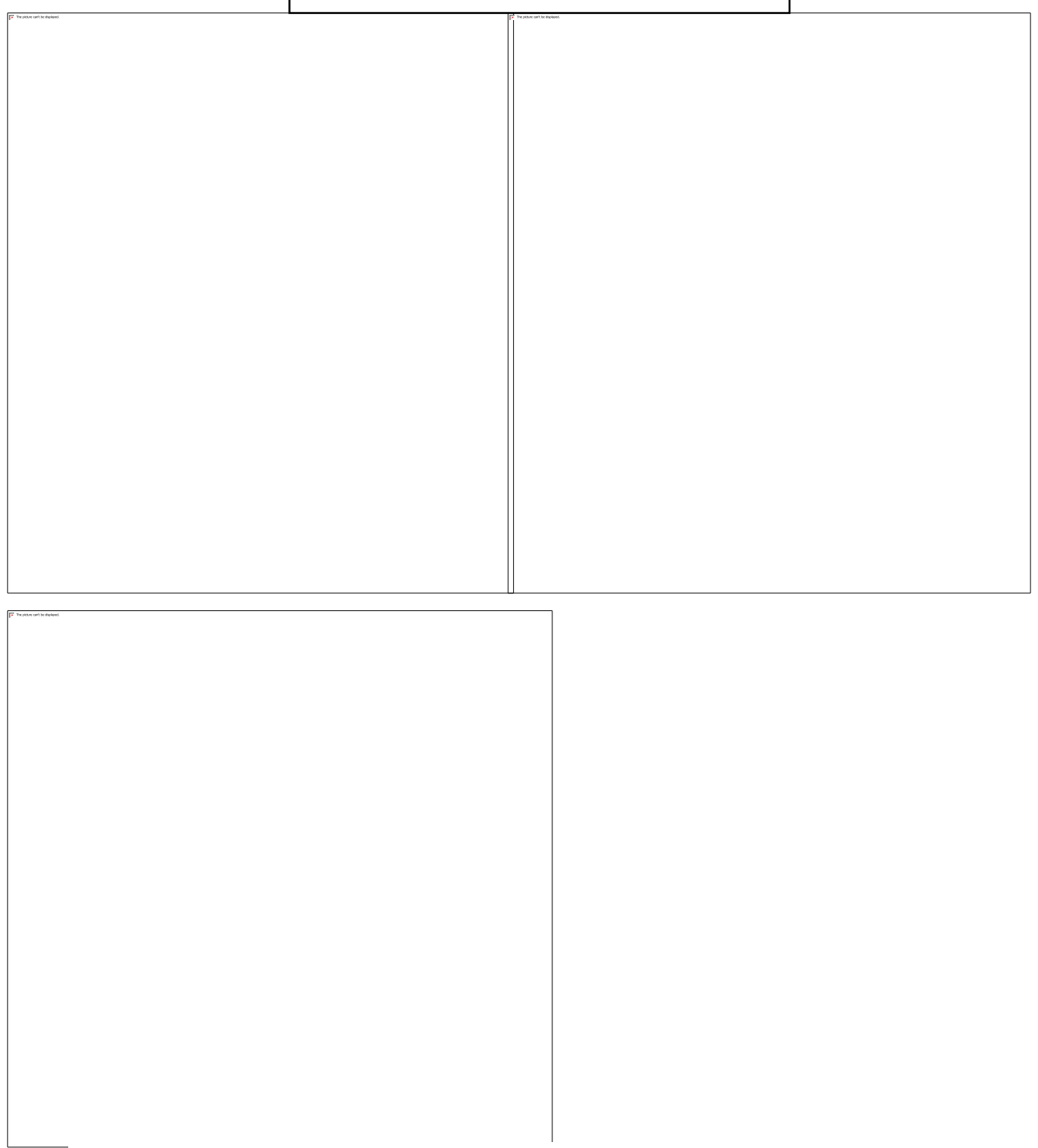

Figure 7. All Variables' QQ plots, continued. 
Histograms of all Variables

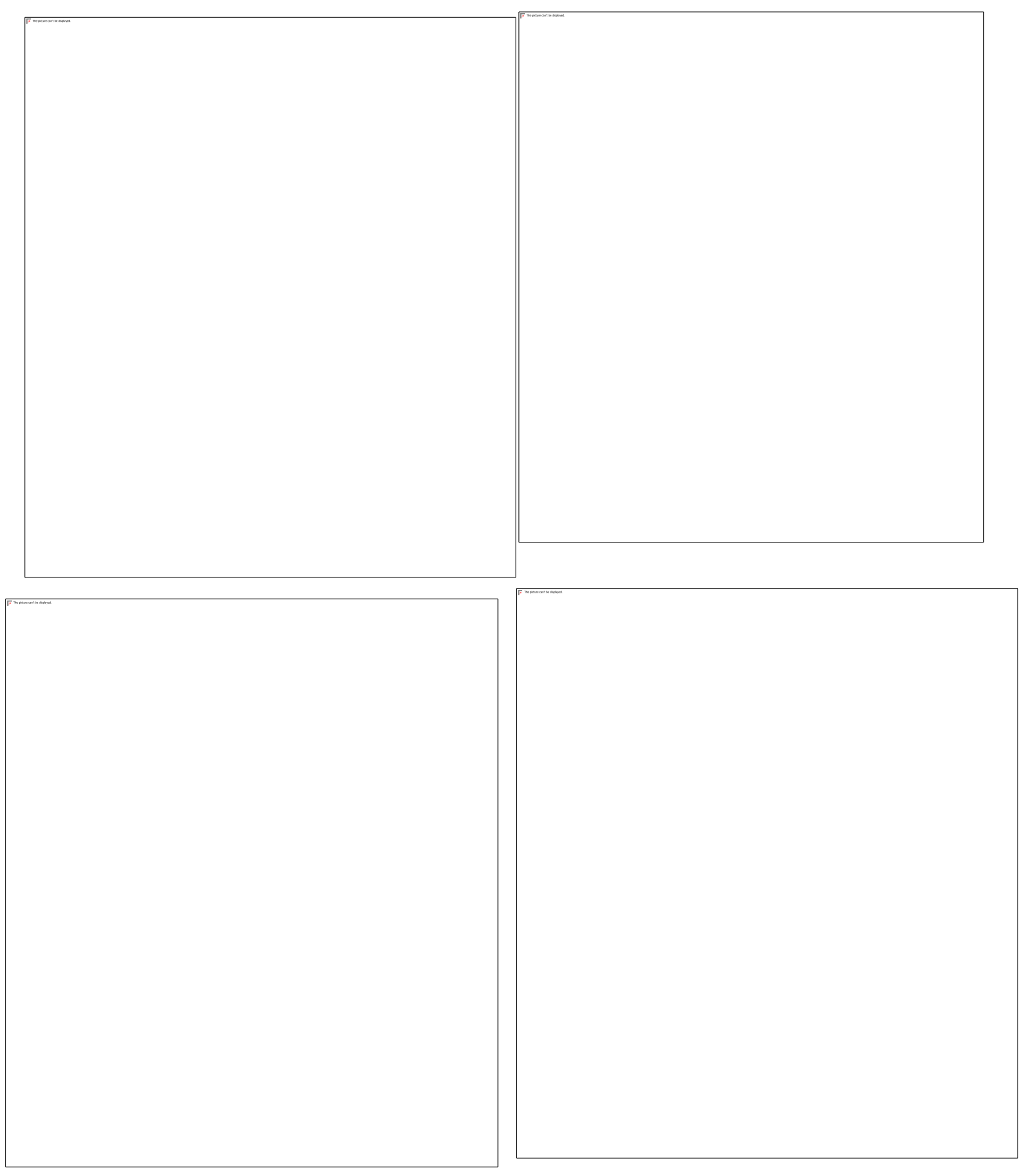

Figure 8. Histograms of all variables 


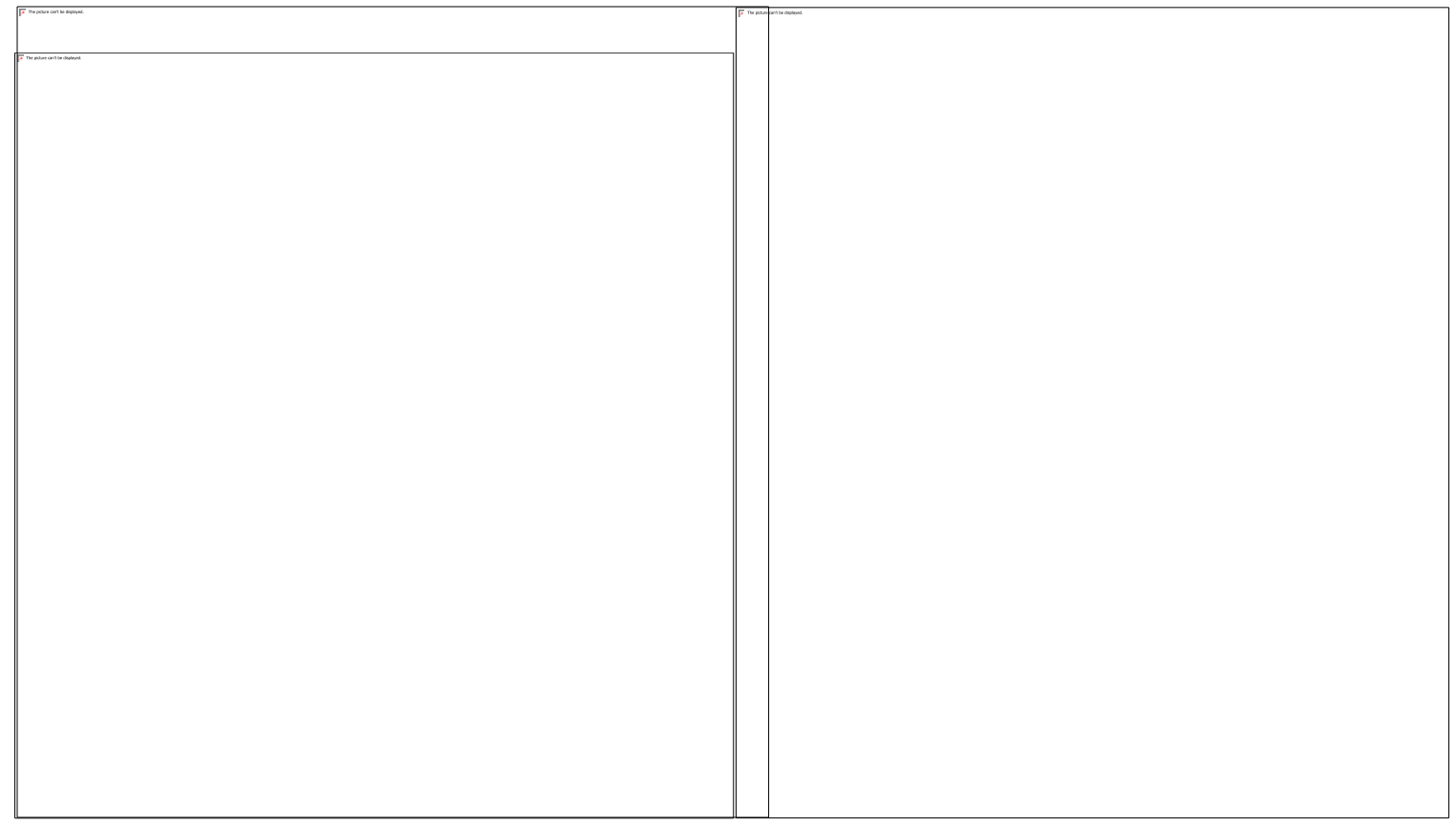

Figure 8. Histograms of all variables 
Biomass Across all Treatments

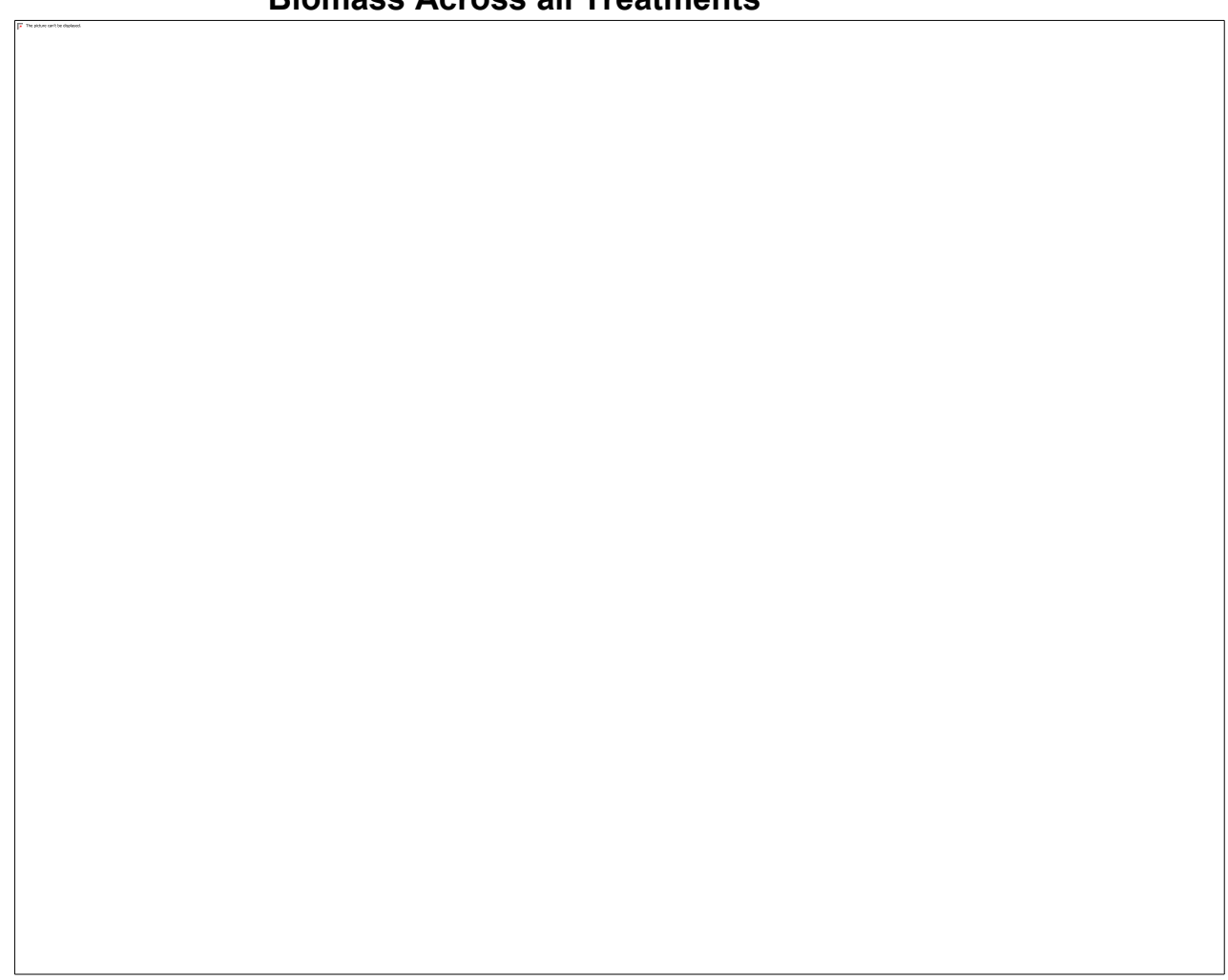

Figure 9. Boxplot of biomass across all treatments.

Table 8. Shapiro-Wilks results seen across all variables

Shapiro-Wilkes Results:

\begin{tabular}{|l|l|l|}
\hline Variable & Test Statistic $(\mathbf{w}=)$ & P-value \\
\hline Canopy Cover & 0.98678 & 0.02278 \\
\hline Chlorophyll Fluorescence & 0.93006 & $2.143 \mathrm{e}-09$ \\
\hline Number of Dead Leaves & 0.96299 & $5.583 \mathrm{e}-06$ \\
\hline Number of Live Leaves & 0.97676 & 0.0004642 \\
\hline Plant Height & 0.98464 & 0.009435 \\
\hline Root Weight & 0.95254 & $3.326 \mathrm{e}-07$ \\
\hline Shoot Weight & 0.955 & $6.412 \mathrm{e}-07$ \\
\hline Biomass & 0.97758 & 0.0006236 \\
\hline Root:Shoot Ratio & 0.96245 & $4.786 \mathrm{e}-06$ \\
\hline
\end{tabular}


PCA of all Variables

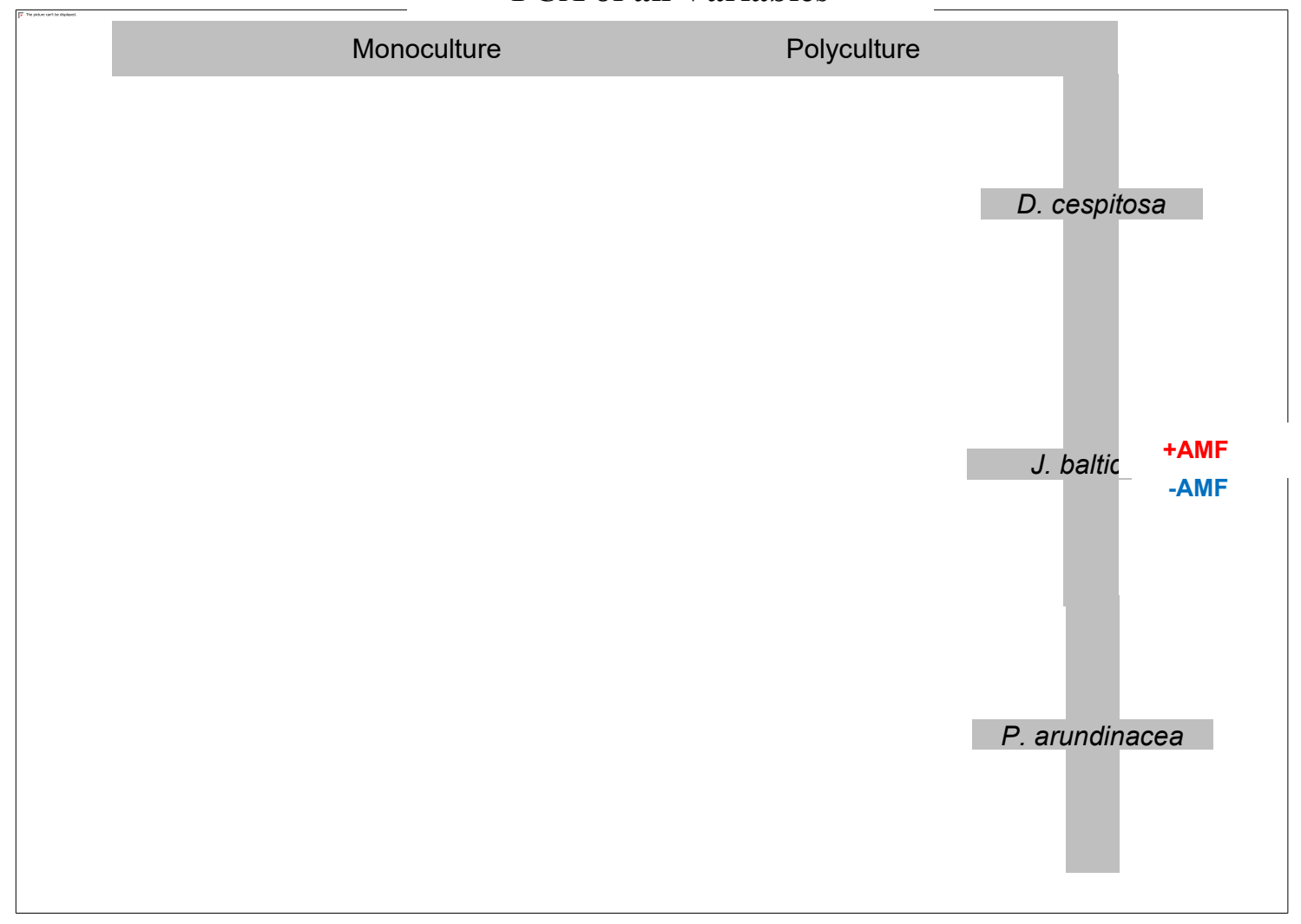

Figure 10. PCA results. The data points from each treatment are highly overlapping and are not clustered indicating that there is little difference in point values between the treatments. The columns are separated by monoculture and polyculture treatments. The rows are by species with $D$. cespitosa, J. balticus and $P$. arundinacea. PC1 (Comp. 1) explains $42 \%$ of the variance of the data and PC2 (Comp. 2) explains $23 \%$. The data points represented in PCA analysis show +AMF and -AMF treatments as seen by all response variables in $\mathrm{PC} 1$ and 2. Treatments were highly overlapping and visually indistinguishable from one another. In total, PC1 (43\%) and PC2 (23\%) accounted for 65\% of variance within the dataset. Eigenvectors quantified the amount of association between each of the measured variables and PC1 and PC2, respectively (Table 3). The largest eigenvectors of PC1 are percent canopy cover, and the related plant mass variables: root to shoot ratio, root weight, biomass. PC2 is associated negatively with the root to shoot ratio, and positively with number of live leaves and chlorophyll fluorescence. These values were used to further explore this data with non-parametric tests performed on singular variables that made significant contributions to accounting for variance within the dataset. 


\section{Broken Stick Model}

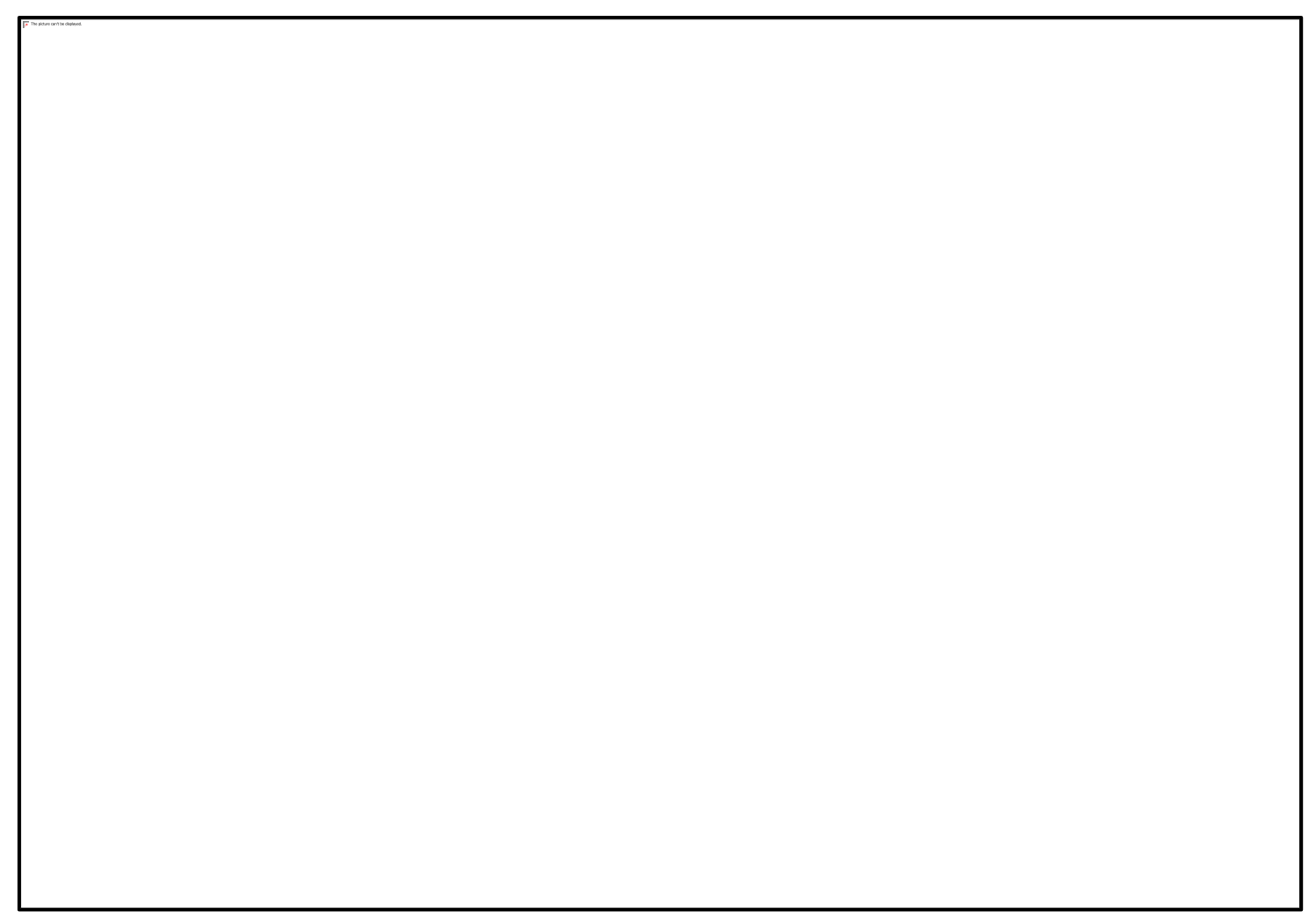

Figure 11. This scree plot shows each principal component and its eigenvalues in grey bars. The broken stick model overlaid indicates that both PC1 And PC2 explain more variance than would be randomly expected. PC1 is shown here to account for $42 \%$ of variance within the dataset, and PC2 accounts for $23 \%$, which totals in $65 \%$ total. 